\title{
1 Effect of Geometrical Parameters of Aluminum-to-Steel Bolted Connections
}

3 Thérèse A. D. Tajeuna ${ }^{1 *}$, Frédéric Légeron ${ }^{2}$, Pierre Labossière ${ }^{3}$, Marc Demers ${ }^{4}$ and Sébastien

$5 \quad{ }^{1} \mathrm{Ph} . \mathrm{D}$ Student

6 Department of Civil Engineering

7 University of Sherbrooke, Sherbrooke, Quebec, Canada, J1K 2R1

8 E-mail: Therese.Tajeuna@USherbrooke.ca

$9 \quad{ }^{2}$ Professor

10 Department of Civil Engineering

11 University of Sherbrooke, Sherbrooke, Quebec, Canada J1K 2R1

12 E-mail: Frederic.Legeron@USherbrooke.ca

$13{ }^{3}$ Professor

14 Department of Civil Engineering

15 University of Sherbrooke, Sherbrooke, Quebec, Canada J1K 2R1

16 E-mail: Pierre.Labossiere@USherbrooke.ca

$17{ }^{4}$ Research Engineer

18 Department of Civil Engineering

19 University of Sherbrooke, Sherbrooke, Quebec, Canada J1K 2R1

20 E-mail: Marc.Demers@USherbrooke.ca

$21{ }^{5}$ Assistant Professor

22 Department of Civil Engineering

23 University of Sherbrooke, Sherbrooke, Quebec, Canada J1K 2R1

24 E-mail: Sebastien.Langlois@USherbrooke.ca

25

$26 *$ Author to whom all correspondence should be addressed 


\section{ABSTRACT}

32 Through experimental and numerical studies, this research work aims to provide directions on the optimal geometric configuration for single-lap and double-lap bolted connection between aluminum alloy 6061-T6 and steel. From experimental test results, the effects of different geometric parameters on the joint strength were discussed. These parameters include the end-distance, the side-distance, the pitch-distance, the plate thickness and the joint eccentricity. Then, the experimental results were compared to predicted results using design references and geometric recommendations proposed by design references were critically examined. The experimental study was complemented by finite element (FE) analysis to extend the study to a larger range of parameters. In addition to the analysis of the geometric parameters listed above, the effects of the gage-distance on the joint strength were studied in the FE analysis. The experimental and finite element results show that a careful selection of geometric parameters can result in the high improvement of the connection strength and failure mode. Limiting the side-distance to the minimum recommended value was found to limit the strength of a connection with two bolts in a column to that of the one-bolt connection. In most cases, bearing was found to govern the strength of the connections. The calculated bearing strengths were found to underestimate significantly the connection strength. Based on these analyses, maximum geometric parameters beyond which there is no further increase of the joint capacity were evaluated and optimum geometric parameters were 50 proposed.

51 Keywords: Bolted connection, aluminum, geometric parameters, single-lap, double-lap, design prediction, finite element.

\section{Introduction}

54 This study was initiated in the context of developing a high strength and low weight portable emergency bridge for railways. The use of aluminum members is a promising option for 
secondary elements in such bridges due to their light weight, corrosion resistance, and low maintenance cost. Aluminum alloy 6061 is easily available and used for many applications. It can be employed without painting if exposed to general atmospheric corrosion. However, when aluminum is attached to steel components, painting the steel components and placing an electric isolator in the joint are required to prevent galvanic corrosion. A critical aspect to consider for the efficient use of aluminum for portable structures is the behavior of aluminum-to-steel connections. In particular, designers would need to optimize the geometric configurations of those connections.

\subsection{Research objective}

The main objective of this research is to provide basic information on the static behavior of aluminum to steel joint in civil engineering applications, compare the experimental results to predicted results using design references, critically examined the geometric recommendations proposed by design reference and to evaluate the maximum geometric parameters beyond which there is no further increase of the joint capacity. This paper is divided into four parts: In the first part, a literature review of aluminum bolted joint is presented. Then, the static test of single-lap and double-lap bolted joints using varying geometric parameters in one and two bolts joints is experimentally studied. Next, calculated joint strengths using equations from three different references, namely Eurocode 9 (EC9) [1], AASHTO LRFD Bridge Design Specifications (AASHTO) [2], and Strength design in aluminum/Commentary on CSA S15705 (CSA-S157) [3] are compared to experimental results. Finally, finite element analysis validated by experimental results is used to extend the data to a large range of parameters. Based on these different analyses, optimum geometric parameters are proposed for one-bolt and two-bolt connections.

\section{Literature review}


80 Among the different joining techniques, bolting appears to be the most practical choice for emergency portable bridges as it can be easily disassembled. However, bolts introduce stress concentration around the bolt-hole where failure can be initiated. When the components are axially loaded, bearing failure, shear tear-out failure, rupture of the net-section, rupture by block shear, yielding of the gross-section and shear failure of the bolt are the six possible modes in which the loaded members can fail. Figure 1 illustrates these six possible failure modes. Equations to calculate the strength for all these failure modes are given in design references. The three design references of interest in this study are: EC9 [1], AASHTO [2] and CSA-S157 [3].

Figure 2(a) presents an example of bolted connections loaded in single-lap and double-lap configurations. In a bolted connection, geometric parameters include: the number of shear planes $x$, end-distance $e$, side-distance $s$, width $w$, pitch-distance $p$, gage-distance $g$, plate thickness $t$, bolt-hole diameter $d_{h}$, bolt diameter $d$, the number of bolts in the row $n$, the number of bolts in the column $m$, and the total number of bolts in the connection $N$. Design references recommend minimum and maximum values for these parameters for the connection of aluminum sections. Table 1 summarises these values for $e, s, p$ and $g$. The recommended minimum distances may be governed by the clearance for bolt heads and driving tools, as indicated in CSA-S157 [3] while, the maximum are governed by local plate buckling and plate thickness. As presented in Table 1, these maximum and minimum can differ from one design reference to another.

100 The main objective of the experimental studies available in the literature is the prediction of 101 the behavior of the aluminum connection for different configurations. Menzemer et al. [4] performed an experimental investigation to establish criteria to estimate the block shear limit

103 state of bolted connection elements. Block shear failure was found to occur by a tensile 104 fracture in the gage-distance of the first inner row and a more gradual shear failure along each 
105 bolt column. Based on their experimental results, an approach to incorporate the connection 106 length into the effective shear strength was proposed. In another paper, Menzemer et al. [5]

107 investigated the bearing strength of three aluminum alloys (5052-H32, 5454-H34 and 3003-

108 H16). Among the key finding, the average ratio of bearing strength to material tensile

109 strength $\left(\sigma_{\mathrm{b}} / f_{\mathrm{u}}\right)$ was higher in configurations with inner aluminum plate than configurations

110 with aluminum outer plates. The effect of bolt pre-load was more relevant in configurations

111 with inner aluminum plate than in configurations with two outer aluminum plates. However,

112 the clamping effect provided either by the bolt pre-load or by the rigidity of the steel cover

113 severely limited the permanent hole elongation. Bearing performance of aluminum bolted

114 connections was also investigated by Wang et al. [6], this time for alloys 6061-T6 and 6063-

115 T5. Bolt-diameter and end-distance were the two parameters studied in the experimental 116 analysis while numerical simulations included also the study of plate thickness. Bearing 117 strength of aluminum was found to be directly proportional to bolt-diameter and sheet 118 thickness. With the increase of end-distance, failure mode was found to change from shear to 119 bearing failure. Bearing strength was linearly proportional to the end-distance up to $e=3 d$.

120 Above this value, bearing strength increasing rate was slower. Based on these results, a simplified relation was proposed to evaluate the impact of the end-distance on bearing strength. The effect of end-distance was also investigated by Kim et al. [7] for single-lap

123 aluminum 6061-T6 plates joined with four bolts all arranged in 2 rows and 2 columns. The 124 joint strength was found to increase with the end-distance up to $5 d$. Above this value, a 125 reduction of the joint strength was observed due to the excessive out-of-plane deformation 126 (curling). Compared to experimental results, the block shear strengths calculated using AISI-

127 S100 [8] and ADM [9] design specifications were underestimated while for curled specimens 128 the design specifications tended to overestimate the joint strength due to the reduction of the 129 capacity caused by curling. Following their experimental study, Kim et al. [10] also 
130 performed a numerical simulation to estimate the structural behavior such as ultimate

131 strength, fracture and out of plane deformation (curling) effect on single-lap aluminum bolted

132 connections. From their parametric study, the necessity to consider this effect in the design of

133 joint strength with long end-distance and side-distance was highlighted. From Tinl et al. [11]

134 study, the average bearing ratio $\left(\boldsymbol{\sigma}_{b} / f_{u}\right)$ at failure of aluminum alloys 5052-H32 and 6061-T6

135 was found to be equal to 1.6 for $e=1.5 d$ and 1.2 for $e=1.25 d$. Compared to the design

136 provisions given by ADM [9] the experimental strengths were found to be larger than the

137 calculated bearing strength using guaranteed minimum mechanical properties.

138 In summary, many values for the spacing of bolts in connections between aluminum plates

139 have been recommended and can also be found in standards. However, except for the end-

140 distance, maximum geometrical parameters beyond which there is no further increase of the

141 joint capacity are not clearly identified. For instance, Kim et al. [10] study indicates that in a

142 four-bolt connection, there is no gain in capacity beyond $5 d$. This suggests that there is still a

143 need to further investigate the geometrical configuration of the joints, especially the

144 maximum distances between bolts, or between bolts and plate edges, in order to optimize the

145 strength of the connection.

146 3. Experimental program

147 3.1. Overview

148 The static test of few experimental configurations was performed in order to understand the

149 behavior of aluminum to steel bolted connections and to obtain sufficient data to validate the

150 FE model. For this investigation, connections with one-bolt loaded in single-lap and double-

151 lap configurations and two-bolt in a column loaded in single-lap configurations were tested.

152 Five configurations were tested for one-bolt single-lap joint. For the first three configurations,

$153 s$ and $e$ equal $1.5 d$ with plate thickness $(t)$ equal to $3.175 \mathrm{~mm}$ (T3), $6.35 \mathrm{~mm}$ (T6) and 9.525

$154 \mathrm{~mm}$ (T9). For the fourth configuration, $s$ and $e$ were taken at $1.5 d$ and $2 d$ respectively with 
$155 t=6.35 \mathrm{~mm}$ while for the fifth configuration $s$ and $e$ equal $2.5 d$ and $t=6.35 \mathrm{~mm}$. Results were used to investigate the effect of $s, e$ and $t$ on one-bolt connections. Then, the effect of joint eccentricity on one-bolt connections was studied by comparing results from the single-lap to those of double-lap with the same end-distance, side-distance and plate thickness $(e=1.5 \mathrm{~d}$, $159 s=1.5 d, t=6.35 \mathrm{~mm})$. Finally, the effect of $s$ on the two-bolt single-lap joint strength was 160 studied. A configuration with $e=3 d, s=2.5 d$ and $p=3 d$ was compared with another configuration for which $e=2.5 d, s=3 d$ and $p=3 d$ both having $t=6.35 \mathrm{~mm}$. Specimens were named with respect to their respective geometric parameters. For example, S15E15T9 stands for single-lap one-bolt joint with $s=1.5 d, e=1.5 d$ and $9.525 \mathrm{~mm}$ thick plates. DS15E15T6 stands for double-lap with $s=1.5 d, e=1.5 d$ and $6.35 \mathrm{~mm}$ thick plates. S25E30P30T6 stands for single-lap two-bolt in a column with $s=2.5 d, e=3 d, p=3 d$ and plate thicknesses of $6.35 \mathrm{~mm}$. S30E30G60T3 stands for single-lap two-bolt in a row with $s=3 d, e=3 d, g=6 d$ and plate thicknesses of $3.175 \mathrm{~mm}$. For all these configurations, ASTM A325 bolts with $12.7 \mathrm{~mm}$ diameter and nominal washer on both sides were used. The bolt-hole diameter $d_{h}$ was approximately equal to $14 \mathrm{~mm}$. Five specimens per configuration were tested except for S30E30G60T3. Three specimens were tested for this configuration for a total of 43 tests.

\subsection{Experimental setup and measurements}

172 The tests were conducted up to failure of the joint in shear using a $500 \mathrm{kN}$ hydraulic testing machine. Figure 2(b) presents the test set-up of aluminum-to-steel connection. The end connections were designed to make the loading axis to coincide with the interface of the two plates so the bolt was primarily loaded in shear. ASTM A325 bolts with $12.7 \mathrm{~mm}$ diameter and nominal washer on both sides were used. The length of the bolt was selected to exclude threads from the shear interface. The bolt was tightened to a snug-fit condition, which referred to the maximum effort of a technician using an ordinary wrench. Therefore, the specimen was considered to be bearing type connection. The load was applied at the rate of 1 
$\mathrm{mm} / \mathrm{min}$ and the load and displacement were recorded by the control system of the universal

181 testing machine.

\subsection{Tensile tests of the materials}

The bolted specimens were taken from different flat bar lots. Flat bars of $63.5 \mathrm{~mm}$ and 76.2 $\mathrm{mm}$ width had a $6.35 \mathrm{~mm}$ thickness; flat bars of $38.1 \mathrm{~mm}$ width had three different thicknesses: $3.175 \mathrm{~mm}, 6.35 \mathrm{~mm}$ and $9.525 \mathrm{~mm}$. The flat bar of $152.4 \mathrm{~mm}$ width had 3.175 mm thickness. Two or three coupons per flat bars were used to investigate their mechanical properties. For aluminum 6061-T6 flat bars, a total of 19 coupons were prepared and tested in tension according to the American Standard Test Method B 557M-02 (ASTM B557-02) [12]. For the $350 \mathrm{~W}$ steel flat bars, 12 coupons were prepared and tested in tension according to the

190 American Standard Test Method A370-12 (ASTM A370-12) [13]. All tested coupons had a reduced section. Strain was measured by an axial extensometer with a gage length of $25 \mathrm{~mm}$ located at the middle of the reduced section.

\section{Experimental results}

\subsection{Coupons tensile tests results}

The mechanical properties of tested aluminum coupons are summarized in Table 2. Stresses were computed from the measured loads data divided by the net-section area of each coupon.

197 The elastic modulus (E) of each coupon was calculated by taking the slope of the elastic 198 portion on its stress-strain curve. Since aluminum does not exhibit a flat plateau at the yield strength as is the case of mild steel, ASTM B 557M-02 [12] suggests to determine the aluminum yield strength $\left(f_{0.2}\right)$ by the offset method at an offset of $0.2 \%$. As presented in table 2 , the strain at maximum tensile stress $\left(\varepsilon_{f u}\right)$ is approximately $10 \%$ while, the strain at $f_{0.2}\left(\varepsilon_{0.2}\right)$ is between $0.40 \%$ and $0.62 \%$. The ultimate tensile strength corresponds to the maximum recorded strength. For coupons $\mathrm{Al}_{\mathrm{A}-1}$ and $\mathrm{Al}_{\mathrm{B}-2}$, it was difficult to evaluate the yield strain and/or yield strength and the elastic modulus because the acquisition of these curves was 
faulty. Tensile strength and elastic modulus reported by design references are also presented in Table 2. Commentary in section 4.2.1 of CSA-S157 [3] recommends for design purposes,

207 that $f_{\mathrm{u}}$ and $f_{0.2}$ shall be the minimum value specified for alloy in the Aluminum Standards and 208 Data Publication (ASD) [14]. For aluminum alloy 6061-T6, this minimum corresponds to that 209 of "shapes" which is $260 \mathrm{MPa}$ and $240 \mathrm{MPa}$ for $f_{\mathrm{u}}$ and $f_{0.2}$ respectively. This value is 210 considered regardless if the material is a plate, shape or sheet. Such recommendation is not 211 specified in [1] and [2]. Therefore, $f_{\mathrm{u}}$ and $f_{0.2}$ were taken as provided in Table 3.2a of [1] and 212 Table 7.4.2.1.1 of [2] for aluminum alloy 6061-T6 "plates".

213 For mild steel, yield point is simply the first stress in a material, less than maximum 214 attainable stress, at which an increase in strain occurs without increase in stress [15]. The 215 material's properties of the 5 different lots were similar. The average ultimate tensile strength 216 and average yield strength were approximately $540 \mathrm{MPa}$ and $370 \mathrm{MPa}$ respectively. ASTM 217 A325 bolts were not tested because the strength of the whole connection was not affected by 218 the capacity of the bolt. Its nominal guaranteed tensile strength is $825 \mathrm{MPa}$ and the nominal 219 shear strength for a bolt of $12.7 \mathrm{~mm}$ diameter is approximately $63 \mathrm{KN}$ considering the shear 220 strength equals to 0.6 times the nominal tensile strength [15]. 4.2. Results of bolted connections

The average experimental failure loads, $P_{\text {exp }}$. standard deviation, Std., and failure modes, $F M$, for each configuration are presented in Table 3. It can be observed that the average maximum experimental loads for each configuration of single-lap one-bolt joint are approximately $40 \mathrm{kN}, 53 \mathrm{kN}$ and $69 \mathrm{kN}$ for S15E15T6, S15E20T6 and S25E25T6 respectively. These load values correspond to $63 \%, 84 \%$ and $109 \%$ of the nominal capacity of the $12.7 \mathrm{~mm} \mathrm{~A} 325$ bolt in shear which is $63 \mathrm{kN}$. By increasing the plate thickness to 9.525 $\mathrm{mm}(3 / 8$ in) with $e=1.5 d$ and $s=1.5 d$, the average recorded load for S15E15T9 equal $57 \mathrm{kN}$ which is $91 \%$ of the nominal capacity of the bolt. For two-bolt joints in a column, the average 

respectively. These loads values correspond to $75 \%$ and $95 \%$ of the nominal capacity of the two bolts. When the two bolts are arranged in one-row, the average failure load is approximately $87 \mathrm{kN}$ for S30E30G60T3 which represent $69 \%$ of the nominal capacity of the

234 two bolts.

\section{5. Analysis of experimental results}

236 As all tested configurations did not have the same material tensile strength, the maximum

237 experimental load $\left(\mathrm{P}_{\text {exp. }}\right.$ ) of each tested joint needs to be adjusted for comparison with other 238 test results. For this purpose, the test results were factored by the ratio of the nominal tensile 239 strength required by CSA-S157 [3] design reference $\left(f_{\mathrm{uCSA}-\mathrm{S} 157}=260 \mathrm{MPa}\right)$ to the average

240 tensile strength of the corresponding coupon, $f_{\mathrm{u}}$ coupon (Equation 1 ).

241 Factored Load $\left(\mathrm{P}_{\mathrm{f}}\right)=\mathrm{P}_{\mathrm{exp} .} \times \frac{f_{\mathrm{u} \text { CSA-S157 }}}{f_{\mathrm{u} \text { coupon }}}$

242 These factored loads were used to investigate the gain in joint strength between different joint configurations. In Figures 3 to 6, the Factored load was used instead of the experimental load because it allowed to better compare the force-displacement curves for the various configurations.

\subsection{Effect of side-distance and end-distance on a one bolt (1X1) single-lap configuration}

247 Figure 3(a) presents the typical failure mode of single-lap aluminum-to-steel one-bolt joints.

248 In this figure, the aluminum plate is on the bottom side while the corresponding steel plate is on the top. The five specimens of each configuration experienced the same failure mode. For S15E15T6, shear tear-out failure of the aluminum plate was observed (Figure 3a). With the increase of the end-distance (S15E20T6), the aluminum plate experienced rupture of the netsection (Figure 3b). A further increase of the end-distance associated with an increase sidedistance (S25E25T6) changed the failure mode of the joint to a bearing failure of plate 
that of S15E15T6 configuration, was assumed to be bearing failure. This assumption was based on the fact that CSA-S157 [3] recommends that "for force directed towards an edge distance, the capacity is governed by shear failure in the connected material up to an end edge distance in excess of two diameters". With S25E25T6 configuration, a limited yielding of the bolt was also observed. Furthermore, the steel plate reaches its plastic state and an ovalization

260 of the bolt-hole in the steel plate was observed.

261 In Figure 3(d), factored typical force-displacement curves of the three configurations are compared. It is observed that the factored load $\left(\mathrm{P}_{\mathrm{f}}\right)$ increased by $32 \%$ and $61 \%$ for S15E20T6 and S25E25T6 respectively as compared to S15E15T6. For design consideration, design references such as [1] and [3] suggest to limit the bearing strength of a connection with $e>2 d$ to that of approximately $2 d$. Experimental results shows that this restriction is acceptable for $\mathrm{s}$ lower than $2 d$. Above this, such restriction underestimates the bearing strength of a one-bolt connection. An observation of the displacement at which failure occurred in the S15E15T6 and S15E20T6 shows that increasing the joint end-distance only did not increase the joint displacement at failure. However, the displacement increased to approximately $10 \mathrm{~mm}$ when both the end and side distances were increased to $2.5 d$. As S25E25T6 leads to bearing failure and to a higher joint strength, it was taken as a reference baseline for two-bolt connections.

The effect of plate thickness was investigated by comparing one-bolt connections with same end and side distances but different plate thicknesses. Figures 4(a), 4(b) and 4(c) present the typical failure mode of specimens S15E15T3, S15E15T6 and S15E15T9 respectively. Results indicate that plate thickness has no effect on the joint failure mode. For this configuration, failure by shear is the observed mode for the three connections.

Figure 4(d) presents the typical force-displacement curves of the three tested configurations. 
$\mathrm{kN}$ respectively. The relationship between the factor load and the plate thickness appears to

281 be not perfectly linear. This effect will be studied further in section 8.1. With S15E15T3, the displacement at failure is approximately $3 \mathrm{~mm}$ while with S15E15T6 and S15E15T9 the displacement at failure is around $7 \mathrm{~mm}$.

284 In Table 3, it can be noted that the factored load obtained with S15E15T9 is only 1.06 times

285 higher than that obtained with S15E20T6 which is 1.5 times thinner but with $e=2 d$. This suggests that a careful selection of the geometric parameters can result in large gains in material weight and cost.

\subsection{Effect of joint eccentricity}

Joint eccentricity is usually present in single-lap configuration resulting in out-of-plane deformation. Plate end-curling observed as a result of such deformation is more prononced in thinner plates with longer end-distance than shorter ones as illustrated in Figure 5(a) and with the double-lap (steel-aluminum-steel) DS15E15T6. In Figures 5(c) and 5(d), failure mode of S15E15T6 is compared to DS15E15T6. As it can be observed, restraining the out-ofplane deformation did not change the failure mode of the joint. Shear tear-out damage is observed on the aluminum plate of both DS15E15T6 and S15E15T6. No significant deformation is observed on the steel plates and on the bolt.

299 Figure 5(e) presents the force-displacement curves of DS15E15T6 and S15E15T6. A gain of $3006 \%$ the factored load $\left(\mathrm{P}_{\mathrm{f}}\right)$ is measured when the eccentricity is restrained. Failure of the 301 DS15E15T6 compared to S15E15T6 occurs earlier in the loading history of the joint. The measured displacement is approximately $5 \mathrm{~mm}$ for DS15E15T6 compared to approximately 7 $\mathrm{mm}$ for S15E15T6. This is probably due to the two outer steel plates. As their rigididy is 3

304 times greater than that of aluminum and due to the restriction of out-of-plane deformation, 
the ability of the aluminum inner plate to freely deform was reduced. As the strength obtained with the double-lap configuration was only few percent higher than that of single-lap, it was not found necessary to pursue the tests with the double-lap configuration. Therefore, the analysis of the two bolts joint was performed only in single-lap configuration.

\subsection{Effect of geometric parameters in two-bolt single-lap configuration}

310 Figures 6(a), 6(b) and 6(c) present the typical failure modes of S25E30P30T6, S30E30P30T6 and S30E30G60T3 respectively. For specimens S25E30P30T6 rupture of the net-section was observed at the aluminum first inner row (Figure 6a). The bolt of the inner row shows sign of

313 shear deformation while the corresponding row on the steel plate shows a light bearing

314 damage. Rupture of the net-section occurs also for S30E30P30T6 on the aluminum first inner

315 row with signs of bearing damage on the two holes (Figure 6b). Signs of bearing damage were also present on the two holes of steel plate while the two bolts reached a plastic state.

317 For S30E30G60T3, failure presented in Figure 6(c) occurs by bearing with hole elongation approximatively equal to 2 times the bolt diameter followed by curling of the aluminum plate. In Figure 6(c), out-of plane deformation of the aluminum plate is observed between the two bolts due to the gage distance, $g=6 d$, taken above the maximum recommended values of EC9 [1] $(g=3.5 d)$ and AASHTO [2] $(g=4.25 d)$ for a $3.175 \mathrm{~mm}$ thick plate. Bearing of the steel plate was also observed while; the two bolts showed signs of damage.

Figure 6(d) presents the typical force-displacement curves of the three configurations. Maximum displacements of $8 \mathrm{~mm}$ and $12 \mathrm{~mm}$ are observed for S25E30P30T6 and S30E30P30T6 respectively. A gain of $31 \%$ of the factored load $\left(\mathrm{P}_{\mathrm{f}}\right)$ is achieved when the side-distance is increased to $3 d$. The factored joint capacity in one-bolt connection (S25E25T6) is equal to $54 \mathrm{kN}$. Doubling the number of bolts with the same side-distance (S25E30P30T6) only increased the joint strength by $46 \%$ because the capacity was limited by the rupture of the net-section and the end-distance has no effect on the joint strength. A 
330 further increase of the side-distance to $3 d$ (S30E30P30T6) leads to 91\% increase in the

331 factored joint strength. As no fracture was observed between the two bolts in both

332 configurations, the pitch-distance $p=3 d$ recommended by [3] is found sufficient to prevent the

333 joint failure on the shear path. Therefore, for the two-bolt in a column with $t=6.35 \mathrm{~mm}$, a

334 side-distance $s$ greater than $3 d$ ( or $w>6 d$ ) is required for the joint to achieve the nominal

335 capacity of the two bolts A325 in shear. This value of $s$ is expected to change with the plate

336 thickness, the number of bolt in the joint, and the bolt size and properties.

337 Figure 7(d) also shows the force-displacement curve for specimen S30E30G60T3. The results

338 of this specimen will be used later to validate the FE model for the two-bolt in a row

339 configuration.

340 6. Comparison between experimental and predicted results

341 The test results of one-bolt and two-bolt connections are compared with the nominal strength

342 prediction obtained using equations recommended by [1], [2] and [3]. As only the nominal

343 strength is considered, strength reduction factors are not used for the calculation of the

344 strength predictions.

345 6.1. Design Equations

346 When failure is predicted to occur in the net-section, all three design references establish the

347 corresponding net-section strength $\left(\mathrm{T}_{\mathrm{r}}\right)$ presented in Equation 2.

348 Nominal net - section strength $\left(\mathrm{T}_{\mathrm{r}}\right)=\left(w-n d_{h}\right) t f_{u}$

349 The three design references do not give a clear guideline of the shear tear-out strength $\left(\mathrm{S}_{\mathrm{r}}\right)$

350 prediction as it is the case of steel structures. As shear tear-out is a particular case of block

351 shear failure also called tear-out in [3], it was assumed that block-shear strength equation in

352 these design references can also be applied to shear tear-out strength. Therefore, the nominal

353 shear-tear-out strength per bolt was evaluated using Equations 3 to 5.

354 CSA - S157 [3] nominal Shear tear - out strength $\left(\mathrm{S}_{\mathrm{r}}\right)=$ et $f_{u}$ 
357 The nominal bearing strength $\left(\mathrm{B}_{\mathrm{r}}\right)$ per bolt is evaluated using Equation (6) to (8) for [3], [1] and [2] respectively. It can be seen in Equation (8) that the bearing strength of the material is required to evaluate the connection bearing strength. This strength was not evaluated for the coupons tested in this study. Therefore, the ratios of $f_{b u} / f_{u}$ and $f_{b y} / f_{y}$ calculated from values provided in [2] design reference Table 7.4.2.1 were used. From the values provided in this reference, the bearing strength of aluminum alloy 6061-T6 $\left(f_{b u}\right)$ equals $2.1 f_{u}$ while the bearing yield strength $\left(f_{b y}\right)$ equals $1.66 f_{y}$. These ratios were used in conjunction with the coupon tensile strength as presented in Equation 8. For $e<2 d$, AASHTO [2] recommends to multiply $\mathrm{B}_{\mathrm{r}}$ by the ratio of $e / 2 d$

$366 \operatorname{CSA}-\mathrm{S} 157[3]$ nominal bearing strength $\left(\mathrm{B}_{\mathrm{r}}\right)=\min \left\{\begin{array}{l}e t f_{u} \\ 2 d t f_{u}\end{array}\right.$

367 EC9 [1] nominal bearing strength $\left(\mathrm{B}_{\mathrm{r}}\right)=2.5 \alpha_{b} d f_{u}$ with $\alpha_{\mathrm{b}}=\min \left\{\begin{array}{c}\frac{e}{3 d_{h}}, \\ 1, \\ \frac{f_{u b}}{f_{u}}\end{array}\right.$

368 AASHTO [2] nominal bearing strength $\left(\mathrm{B}_{\mathrm{r}}\right)=\min \left\{\begin{array}{c}d t f_{b y}=1.66 d t f_{y} \\ d t f_{b u} / 1.2=1.75 d t f_{u}\end{array}\right.$ 6.2. Analysis of the predicted results Table 3 column 5 to 13 lists the predicted failure modes and failure loads of the three design references. The material tensile strengths obtained from the tested coupons were used for this calculation. Therefore, the predicted load $\mathrm{P}_{\mathrm{n}}$ should be compared to the predicted experimental load $\mathrm{P}_{\text {exp }}$. The experimental to predicted ratios are also reported in Table 3.

374 For connections S15E20T6, S25E30P30T6 and S30E30P30T6, experimental study reveals a

375 failure mode by net-section. However, with EC9 [1] and AASHTO [2] bearing strength was 376 found to govern the design prediction of these three configurations. Failure prediction by 377 CSA-S157 [3] was consistent with the experimental failure for S15E20T6 and S25E30P30T6. 
378 However bearing strength governs the design prediction for S30E30P30T6. With [3], the net379 section capacity was also well predicted with a maximum difference of $14 \%$ compared to 380 experimental failure load. The strength of these connections was underestimated by $20 \%$ to $38164 \%$ compared to experimental results when bearing failure was the predicted mode.

382 For connections S15E15T3, S15E15T6, S15E15T9 and DS15E20T6, it was assumed in the 383 experimental analysis that the observed failure mode is shear tear-out (instead of bearing) 384 because of $e<2 d$ as suggested in [3]. However, with [1] and [2] design predictions, bearing strength was found to govern the design prediction. Failure prediction by [3] was consistent with the experimental failure as the shear strength equation (Equation 3) is equal to the lower

387 bound of bearing strength (Equation 6). With [1] and [2], the predicted strength was found to

388 be very conservative with a maximum difference of $60 \%$ compared to experimental results. 389 As for [3], a better prediction of the strength was obtained with a maximum difference of $20 \%$ compared to experimental results.

391 For connections S25E25T6 and S30E30G60T3, all three design references predicted a

392 bearing failure which is consistent with the experimental failure mode. However, the bearing 393 strength prediction of these three references underestimated the connection strength by $30 \%$ 394 to $106 \%$ as compared to experimental results. This is due to the fact that design references 395 limit the bearing strength to approximately twice the ultimate tensile strength. For $e>2 d$, such 396 limitation underestimates the connection strength.

397 More data are required to better comprehend the relationship between different geometric 398 parameters and the joint strength and to develop design equations capable of providing an 399 accurate prediction of the joint strengths. Finite element analysis is a good tool to extend such 400 data.

\section{$401 \quad$ 7. Finite element analysis}

402 7.1. Overview of the finite element model 
403 A finite element (FE) analysis was performed to investigate the strength of aluminum bolted 404 joints with the commercial software ADINA 8.7.3. The analysis started with a validation 405 study. The experimental results were used to validate the FE results. This analysis was 406 followed by a parametric study where a 3D FE analysis was used to study the effect of plate 407 thickness and verify the assumption made in section "Effect of plate thickness". For this 408 verification, $t=3.175 \mathrm{~mm}, 6.35 \mathrm{~mm}, 9.525 \mathrm{~mm}, 12.7 \mathrm{~mm}, 15.875 \mathrm{~mm}, 19.05 \mathrm{~mm}, 25.4 \mathrm{~mm}$ with the constant values of $e=1.5 d$ and $s=1.5 d$ were considered. Then, the effects of increasing the end-distance $(e=1.5 d, 2 d, 3 d, 4 d, 5 d)$ and the side-distance $(s=1.5 d, 2 d, 2.5 d$, $3 d, 4 d, 5 d$ ) in one-bolt connection were analyzed using 2D FE analysis. Finally, the optimum

412 geometric parameters for two-bolt connections either aligned parallel or transversal to the 413 loading direction were investigated. The end-distance and the side-distance were varied from $4141.5 d$ to $5 d$ as in one-bolt configuration while increasing the pitch-distance $(p=2 d, 3 d, 4 d, 5 d)$ 415 for two-bolt parallel or the gage-distance $(g=2 d, 3 d, 4 d, 5 d)$ for two-bolt transversal to the 416 loading direction were considered. In line with the experimental investigation, maximum 417 geometric parameters beyond which there is no increase in the joint strength were evaluated.

418 Results obtained from this analysis were also used to evaluate the optimum parameters of one 419 and two bolts connection for different plate thicknesses, bolt sizes and bolt grades. A linear 420 relationship between the joint strength and both the plate thickness and bolt size was assumed. These optimums were chosen based on the values at which the nominal shear 422 strength of a high strength bolt A307, A325 and A490 is reached. The recommendation of 423 AASHTO [2] to limit the net-area $\left(A_{n}\right)$ of the connecting element to the maximum value of $42485 \%$ the gross-area $\left(A_{g}\right)$ of the plate was also taken in consideration. Although such 425 requirement is not specified for aluminum structures, it was considered for choosing the side 426 and gage distances to make sure an economic design is identified.

$427 \quad 7.2$ Analysis assumptions 
In the experimental study of the aluminium-to-steel connection, failure of the joint was due to the aluminum fracture. Therefore, to reduce the computation time, only the aluminum plate and bolt were modeled in the finite element (FE) analysis. To ensure that the model reliability will not be affected with such simplification, a 3D model, which includes the aluminum plate, the steel plate and the bolt (FE_3DAS) was also computed. The results obtained with the 2D (FE_2DA) and 3D (FE_3DA) simplified models were compared to FE_3DAS and experimental results. As bolts were tightening to a snug-fit condition (bearing type connection), the bolt preload was neglected. The bolt preload was also not considered in the FE analysis by [10] for the same preload condition. Figures 7(a) and 7(b) present the typical FE_3DAS and FE_3DA models used for this analysis.

438 For model validation, all configurations tested in the experimental program were analysed. Material properties of these configurations are shown in Table 2. In the static environment of ADINA, the aluminum and steel plates were modeled as a material with bilinear elastoplastic behavior. The 3D solid element with 8 nodes per element and 3 degrees of freedom was considered. The analysis assumptions were large displacement and strain. Full Newton method was used for the iteration. The bolt was modeled as a cylinder of $12.7 \mathrm{~mm}$ diameter.

444 Contacts between the bolt and the plates were modeled by contact elements available in the FE software. The contact interface were generated as a pair of surface elements. On this interface, a bolt was defined as a target surface and the bolt-hole as a contactor surface. This

447 assumption was based on the fact that the strength of the steel bolt is greater than that of 448 aluminum and steel plates. No friction was considered on this interface. For the 3D model 449 containing the steel and aluminum plates (3DAS), fixed boundary condition was applied on 450 the aluminum far end plate edge $(X=Y=Z=0)$ and a uniform pressure was applied in the 451 longitudinal $\mathrm{z}$ axis of the far end plate edge of the steel plate (Figure 7a). For the 3D 452 simplified model containing only the aluminum plate (3DA), fixed boundary condition was 
applied on the bolt $(\mathrm{X}=\mathrm{Y}=\mathrm{Z}=0)$ and a uniform pressure was applied in the longitudinal $\mathrm{z}$ axis

454 of the far end plate edge of the aluminum plate (Figure $7 \mathrm{~b}$ ). The external load was incrementally applied on the structure. Once the deformation of the material at $f_{u}\left(\varepsilon_{f u}\right)$ was reached, the structure diverged. The load to which the structure diverged was taken as the maximum capacity that the joint can support.

458 For the parametric study, $f_{0.2}=279 \mathrm{MPa}, f_{\mathrm{u}}=310 \mathrm{MPa}, \varepsilon_{0.2}=0.4 \%$ and $\varepsilon_{f u}=10 \%$ were considered. A 3D FE analysis was first used to investigate the effect of plate thickness. Then, to further reduce the computational process, a 2D FE analysis was considered to evaluate the effects of $e, s, p$ and $g$. In addition to the FE modeling assumptions described above, six degrees of freedom and 9 nodes per element were used for 2D FE model (2DA). The bolt was modeled as a half cylinder and the contact feature available in the software was used. The parameters: $e, s, p$ and $g$ were consecutively changed while $d=12.7 \mathrm{~mm}$ and the input plate thickness $(t=6.35 \mathrm{~mm})$ were kept constant.

\subsection{Model validation}

467 Figure 7(c) to 7(e) present the post-processing strain distribution of the FE model. Based on 468 the plastic strain distribution along a given failure path of the model, the joint failure mode was defined. For example, for net-section failure, plastic strains are developed across the centerline of the bolt-hole in the net-section path (Figure 7c). For shear tear-out failure presented in Figure 7(d) plastic strains are developed between the side of the bolt-hole up to the free end edge of the plate while in bearing failure presented in Figure 7(e), plastic strains are limited ahead of the bolt hole in the bearing path and barely reach the free end edge of the 474 plate.

In Figure 8, the typical force displacement curves obtained in the FE analysis are compared to that of experimental results. In general, no significant difference in the failure loads are 477 observed between the three different models. In Figure 8(a) and 8(b) it can be observed that 
478 the elastic portion of the force-displacement history of FE_3DAS is stiffer than that of 479 FE_3DA and FE_2DA. On the other hand, it can be observed that the curves of FE_3DA and 480 FE_2DA in Figure 8(a) to 8(d) are quite consistent with that of experimental results up to the 481 peak load at which the FE models stop. Therefore, the simplified 2D (FE_2DA) and 3D 482 (FE_3DA) models will be used for the rest of the study.

483 In Table 4, the ultimate loads and failure modes obtained from simplified 2D and 3D FE analyses of one and two bolts connections are compared to the average failure loads obtained in the experimental analysis. As it can be observed, both $2 \mathrm{D}$ and $3 \mathrm{D}$ results are in good agreement with experimental results, FE failure loads are mostly conservative. The ratios of experimental to predicted results are within $11 \%$ difference for 3D and $2 \mathrm{D}$ models. The observed FE failure modes were also consistent with the experimental failure mode. Therefore, the 3D and 2D models are enough reliable to be used for the parametric analysis.

\section{Parametric simulation and analysis of the results}

Following the satisfactory agreement between 2D, 3D FE models and experimental results, a parametric study was carried out. The results obtained from the parametric simulation are 493 presented in Figure 10, Tables 5 and 6.

\subsection{Effect of plate thickness in one-bolt connection}

495 The effect of plate thickness on the joint strength were analysed by keeping the material properties $\left(f_{0.2}=279 \mathrm{MPa}, f_{\mathrm{u}}=310 \mathrm{MPa}, \varepsilon_{0.2}=0.4 \%\right.$ and $\left.\varepsilon_{f u}=10 \%\right)$ and $e=s=1.5 \mathrm{~d}$ constant with

497 varying values of $t(t=3.175 \mathrm{~mm}, 6.35 \mathrm{~mm}, 9.525 \mathrm{~mm}, 12.7 \mathrm{~mm}, 15.875 \mathrm{~mm}, 19.05 \mathrm{~mm}, 25.4$ mm). Results obtained from this simulation are presented in Figure 9. Figure 9(a) shows the plastic strain distributions of S15E15T25, S15E15T12 and S15E15T3. Failure occurs by

500 shear tear-out regardless of the size of the plate thickness. In Figure 9(b), it can be observed 501 that the relationship between the plate thickness and the joint strength is to a certain extent 502 linear in the model. The experimental results obtained for S15E15T3, S15E15T6 and 
503 S15E15T9 are also presented in this figure. It was observed experimentally that the 504 relationship between the plate thickness and the average joint strength was not perfectly

505 linear. However, by tracing all the data obtained experimentally for these configurations in

506 Figure 9(b), the linear relationship between the plate thickness and the joint strength is an 507 acceptable simplification. The possible non-linearity of this relationship would need to be 508 studied with additional experimental tests. In particular, for plates with large thicknesses, 509 which are realistic in the context of bridge construction, no experimental data was found in 510 the literature and therefore the numerical results proposed in this study would need to be 511 further studied with experimental tests to confirm the trends observed.

512 For the evaluation of the optimum parameter, the linear relationship between the bolt 513 diameter and the plate thickness was assumed as demonstrated by the experimental study of 514 Wang et al. [6] and section 8.1. Results obtained from the FE analysis and presented in Table 5155 and 6 were used to extrapolate the strength of connections with different plate thicknesses 516 and bolt diameters. Tables 7 to 9 present the proposed optimum for values of $6.35 \mathrm{~mm} \leq t \leq$ $51725.4 \mathrm{~mm}$ and $12.7 \mathrm{~mm} \leq d \leq 25.4 \mathrm{~mm}$. In these tables, cells with no value are those from which 518 the plate thickness could not sustain the capacity of the bolts or which required a side519 distance larger than the maximum recommended values of both [1] and [2] and from which 520 the ratio of $A_{n} / A_{g}>0.85$. The following paragraphs described some of the important results 521 obtained in the parametric simulation and the criteria behind the choice of optimum 522 parameters.

523 8.2. Optimum end-distance $(e)$ and side-distance $(s)$ in one-bolt connection

524 Figure 10(a) presents the effects of the end-distance (on the positive x-axis) and the side525 distance (on the negative $\mathrm{x}$-axis) on the failure load for one-bolt joint as obtained by the FE 526 analysis for $t=6.35 \mathrm{~mm}$ and $d=12.7 \mathrm{~mm}$. The predicted strengths of the one-bolt joint using 527 the maximum and minimum $e$ and $s$ recommended by EC9 [1] were also evaluated and are 
528 presented in this figure. These minimum are equal to $1.2 d$ for $s$ and $e$ while the maximum is $4 t+40 \mathrm{~mm}$ for both $s$ and $e$ which corresponds to $5.15 d$ for $t=6.35 \mathrm{~mm}$ and $d=12.7 \mathrm{~mm}$. FE results show an increase of the joint capacity with the increase of $s$ and $e$ up to a limit value of $3 d$ and $4 d$ respectively. Table 5 shows the FE results of one-bolt connection. It can be observed that the strength of the connection is governed by net-section failure at $s<e$, shear tear-out failure for $e \leq s \leq 2 d$ and bearing failure for $e$ and $s>2 d$. Comparisons between the strength obtained from FE analysis at the limits of $3 d$ and $4 d$ for $s$ and $e$ respectively reveals that the measured gain is $33 \%$ and $75 \%$ higher than the predicted strength at maximum and minimum values recommended by [1]. These values are consistent with the maximum values recommended by [1], which are $5.15 d(4 t+40 \mathrm{~mm})$ for both $s$ and $e$. For design consideration, design references such as [3] suggest to limit the bearing strength of a connection with $e>2 d$ to that of $2 d$. Figure 10(a) shows that this restriction is acceptable for $s$ lower than $2 d$. Above this, such restriction underestimates the bearing strength of a one-bolt connection. From Table 5 , the values of $s=2 d$ and $e=3 d$ were found sufficient to improve the connection strength to that of one bolt A325 nominal shear strength with $d=12.7 \mathrm{~mm}$ and $t=6.35 \mathrm{~mm}$. With the value of $s=2 d$, the ratio of $A_{n} / A_{g}=0.75$ which is lower than the limit ratio of 0.85 is obtained. The optimum parameters of one-bolt with varying bolt sizes, plate thickness and bolt grade are presented in Table 7 . It can be observed that optimum values are related to the bolt diameters, bolt grade and plate thickness. For bigger bolt size $(d=25.4 \mathrm{~mm})$ or A490 bolt

547 grade, these optimums can reach the limit of $3 d$ and $4 d$ for $s$ and $e$ respectively with $A_{n} / A_{g}$ $548<0.85$.

549 8.3. Evaluation of the optimum geometric parameters for two-bolt joint in a column

550 Figure 10(b) presents the effects of geometric parameters for the joint with two bolts parallel to the loading direction, as obtained from the FE analysis for $t=6.35 \mathrm{~mm}$ and $d=12.7 \mathrm{~mm}$. The predicted strengths of the two-bolt joint using the maximum and minimum $e, s$ and $g$ 
recommended by [1] are also presented. The maximum and minimum $e$ and $s$ are the same as in one-bolt joint while the limit values of $p$ are: $2.4 d \leq p \leq 7 d(14 t)$. On the positive $\mathrm{x}$-axis of Figure $10(\mathrm{~b})$, the effect of $e$ with $s=1.5 d, 3 d$ and $4 d$ and varying pitch ( $p=2 d$ to $5 d$ ) is depicted. Except for $s \geq 4 d$, it can be observed that at $e \geq 2 d$, $e$ has a negligible effect on the joint strength. This value of $2 d$ is consistent with the minimum limit of $e$ recommended by [2]. For a constant value of $s$, the observed increase in strength is related to the increase of the pitch-distance up to $p=3 d$. Above this value, the plateau indicates that with the increase of $e$ and $p$, the joint strength continues to increase with $s$. This last effect is represented on the negative $\mathrm{x}$-axis for a constant value of $e=3 d$. It is shown that the increase of the joint strength is consistent with the increase of the side-distance. From $s=1.5 d$ to $3 d, p$ has no effect on the joint strength. This is because the net-section strength governs this value as shown in Table 6 for $1 \mathrm{X} 2$ configuration. Above $s=3 d$, the effect of $p$ becomes evident while $s$ remains the main parameter affecting the joint strength. FE results presented in Table 6 for $1 \mathrm{X} 2$ configuration reveal that the failure mode occurs by bearing for $s>3 d$. The effect of $(e)$ on the joint strength as calculated with [1] shows that limiting the value of $s$ to the minimum values $(s=1.5 d)$ will limit the strength of the two-bolt joint in a column to that of one-bolt joint with similar width. Similar interpretation can be obtained from FE results. For example in Table 5 for $s=1.5 d$, $e=2 d$, the load of one-bolt connection is equal to $47.8 \mathrm{kN}$. In Table 6 , for two-bolt in a column, $s=1.5 d, p=3 d$, failure load is equal to $48.4 \mathrm{kN}$. Therefore, the choice of $s$ should be consistent with the number of bolts in the column and the plate gross area $\left(A_{g}\right)$. For this

573 configuration, $s=3 d$ was found sufficient to improve the joint strength to the nominal capacity of the two bolts in shear. This value is lower than the maximum limit recommended by [1], although $9 \%$ higher than that of [2]. On the other hand, the ratio of $A_{n} / A_{g}=0.82<0.85$ is obtained. With this choice of $s$, the values of $p$ and $e$ can therefore be limited to $3 d$ and $2 d$

577 respectively for $t=6.35 \mathrm{~mm}$ and $d=12.7 \mathrm{~mm}$. The optimum parameters of two-bolt in a 
column with varying bolt sizes, plate thickness and bolt grade are presented in Table 8 . The optimum value of $s$ is found to vary with the plate thickness and the strength of the bolts and should be limited to $4 d$ although at this value, $A_{n} / A_{g}=0.86$.

Figure 10(c) presents the effects of joint parameters for two-bolt in a row, as obtained from the FE analysis for $t=6.35 \mathrm{~mm}$ and $d=12.7 \mathrm{~mm}$. The predicted strengths of the two-bolt joint using the limit values recommended by [1] are also presented. These limit values of $g$ are $2.4 d \leq g \leq 7 d(14 t)$. The effect of $e$ presented on the positive $\mathrm{x}$-axis is evaluated by considering a $3 d$ side-distance with varying end-distance ( $e=1.5 d$ to $5 d$ ) and gage-distance ( $g=2 d$ to $5 d$ ). It can be observed that both $g$ and $e$ have an effect on the joint strength. The effect of $e$ becomes negligible at $4 d$ with $g>3 d$ while the joint strength continues to increase with the gage-distance. The effect of $s$ with a constant $e=3 d$, varying side-distance $(s=1.5 d$ to

$5905 d$ ) and gage-distance ( $g=2 d$ to $5 d$ ) is shown on the negative $\mathrm{x}$-axis of Figure $10(\mathrm{c})$. It can be observed that the joint strength increases with $s$ up to $3 d$ while it continues to increase with $g$. At minimum recommended values of $s$ and $g$, the predicted strength of the connection is governed by net-section failure. At maximum recommended values, bearing is the predicted failure mode. FE results presented in Table 6 for $2 \mathrm{X} 1$ configuration show that block-shear and bearing are the observed failure modes for $s \geq 2 d$ while net-section failure is observed with narrow side-distance $(s=1.5 d)$ and shear tear-out failure for short end-distance $(e=1.5 d)$. With $e=3 d$, limiting $s$ and $g$ to the minimum values recommended by [1] $(s=1.2 d$ and $g=2.4 d)$

598 limits the predicted nominal strength to that of the one-bolt joint with similar width.

599 However, with the same end-distance, increasing $s$ to $3 d$ and simultaneously considering $600 g=3 d$ improve the predicted nominal strength to that of the two bolts (A325). With these 601 values, the ratio of $A_{n} / A_{g}=0.78$ which is lower than the limit of 0.85 is obtained. From values 602 reported in Table 6 and the above analysis, $e=3 d, s=3 d$ and $g=3 d$ are proposed for $d=12.7 \mathrm{~mm}$ 
and $t=6.35 \mathrm{~mm}$. The proposed values are between the limits recommended by [1] although $e$

604 and $s$ are 9\% above the maximum recommended by [2]. The optimum parameters of two-bolt

605 in a row with varying bolt size, plate thickness and bolt grade are presented in Table 9. It is

606 shown that for $s=3 d$, the proposed optimums can reach the limit of $g=5 d$ and $e=3 d$. However,

607 for this value of $g$, the $A_{n} / A_{g}=0.82$.

\section{9. Conclusion}

609 The aim of this study was to critically examine the recommendations of three design

610 references namely EC9 [1], AASHTO [2] and CSA-S157 [3], to evaluate the maximum

611 geometric parameters beyond which no major increase of joint strength is observed and to

612 propose optimum geometric parameters for one-bolt and two-bolt connections. The chosen

613 optimum was based on the values at which the shear strength of the three grades of bolt

614 (A307, A325, and A490) is reached and on the limit of $A_{n} \leq 0.85 A_{g}$. It was found that the joint

615 geometric parameters have a high impact on the load performance and failure mode. In

616 summary:

617 - For one-bolt configuration, experimental analysis on aluminum-to-steel connections

618 shows that to achieve bearing failure, $e$ and $s$ should not be less than $2.5 d$. Above this,

619 bearing damage was observed on steel plate and on the bolt. It was shown from the

620 finite element analysis that maximizing the geometric parameters can result in an

621 increase of the joint strength of more than $75 \%$ compared to the minimum values

622 recommended by the design references. Although maximum $e$ and $s$ was observed at

$6234 d$ and $3 d$ respectively, the optimum values were found to be related to the bolt

624 diameter, bolt grade and plate thickness. The proposed optimum were within the limit

625 of EC9 [1] and/or AASHTO [2] recommended values and the ratio of $A_{n} / A_{g}<0.85$.

626 - For two-bolt connections in a column, it was observed from the experimental study

627 that pure bearing failure is not likely to occur. The pitch $p=3 d$ was found sufficient to 
sustain the joint and prevent the failure between the holes. Finite element analysis indicates that the side-distance is the main parameter that controls the strength of the connection. Limiting the side-distance to the minimum recommended value $s=1.5 d$ was found to limit the strength of two bolts in a column to that of the one bolt connection. The effect of $p$ was evident after $3 d$ while $e>2 d$ was found to have limited effect on the joint strength. For this configuration, the proposed optimum parameters should be taken at $e=2 d, p=3 d$ while $s$ varies with the plate thickness and the nominal shear strength of the bolts and should be limited to $4 d$ although at this value, $A_{n} / A_{g}=$ 0.86.

- For the configuration with two-bolt in a row, the strength of the connection was found to increase with $s$ and $e$ up to the limit value of $3 d$ and $4 d$ respectively. The increase of the joint strength was consistent with the increase of $g$. With the proposed optimum, the strength of connection reached the nominal shear strength of the bolts and the ratio of $A_{n} / A_{g}$ was less than 0.85 .

- Compared to double-lap connection, the effect of the out-of-plane deformation observed experimentally in the single-lap configuration with $s=1.5 d$ and $e=1.5 d$ did not change the failure mode of the aluminum specimen. However, restraining the joint eccentricity with a double-lap configuration was found to slightly improve the joint strength. Out-of-plane deformation was more pronounced in connection with long end-distance and thinner plate.

- Predicted failure modes were not always consistent with experimental failure mode. In most cases, bearing was found to govern the strength of the connections. The calculated bearing strengths were found to underestimate significantly the connection strength. Compared to EC9 [1] and AASHTO [2], CSA-S157 [3] was found to provide a better prediction of the failure mode and failure load of the connections. 


\section{ACKNOWLEDGEMENTS}

654 The financial support provided by Natural Science and Engineering Research Council of

655 Canada (NSERC) and Centre québecois de recherche et de développement de l'aluminium 656 (CQRDA) is acknowledged.

657

\section{REFERENCES}

659 [1] EC9. (2007). "Eurocode 9: Design of aluminum structures". European Committee for 660 Standardization, Brussels.

661 [2] AASHTO (2010). “AASHTO LRFD Bridge Design Specifications”, American

662 Association of State Highway and Transportation Officials, $5^{\text {th }}$ edition.

663 [3] CSA-S157 (2007). "Strength Design in Aluminum/Commentary on CSA S157-05,

664 Strength design in aluminum”. Canadian Standards Association.

665 [4] Menzemer, C.C., Fei, L., Srivastsan, T.S. (1999). "Design Criteria for Bolted connection 666 elements in aluminum alloys 6061”, Journal of Mechanical Design, Vol. 121, p. 348-358.

667 [5] Menzemmer, C.C., Ortiz-Morgado, R. and Iascone, R. (2002). “An investigation of 668 bearing strength of three aluminum alloys", Materials Science and Engineering A327, p. 203669212.

670 [6] Wang, Y., Yuan, H., Shi Y., Zhang, G. (2011). "Bearing Performance and design method 671 of aluminum alloy bolted connections", Applied Mechanics and Materials, Vols. 71-78, p. $672 \quad 882-889$.

673 [7] Kim, T., Jo Y.H., Kim, S. and Lee, Y.T. (2012). "Ultimate Behavior of Single Shear 674 Bolted Connections with Thin-walled Aluminum Alloys (6061-T6)", Advanced Materials 675 Research, Vols. 446-449, p. 3441-3445.

676 [8] AISI S100 (2007). "American Iron and Steel Institute”. North American Specification for 677 the Design of Cold-Formed Steel Structural Members.

678 [9] ADM. (2010). "Aluminum Design Manual”. The Aluminum Association, Washington, 679 D.C.

680 [10] Kim, T., Jo Y.H. and Choi, Y.C. (2012). "Numerical Investigation on Structural 681 Behavior and Curling influence of aluminum alloy bolted Connections", Applied Mechanics 682 and Materials, Vols. 166-169, p. 885-889.

683 [11] Tinl, N., Menzemer, C.C., Manigandan, K. and Srivatsan, T.S. (2013). "The Bearing 684 Strength and Fracture Behavior of Bolted Connectionns in Two Aluminum Alloys", Journal 

0643-7.

[12] ASTM B557-02 (2002). "Tension testing wrought and cast aluminum and magnesium-

692 Inc.,Washington, DC.

693 [15] Kulak, G. L., Adams, P.F., Gilmor, M.I. (1998). "Limit States Design in Structural

694 Steel" Canadian Institute of Steel Construction, $5^{\text {th }}$ edition.

\section{List of Figures}

697

Figure 1. Failure modes: (a) Bearing, (b) Net-section, (c) Shear tear-out, (d) Block-shear,

(e) Gross-section yielding, (f) Bolt shear

Figure 2. (a) Typical bolted joints in single-lap and double-lap arrangements. (b) Test set-up

of aluminum to steel connection

Figure 3. Effect of $s$ and $e$ on one bolt single-lap joints: Damage on: (a) S15E15T6, (b)

S15E20T6, (c) S25E25T6. (d) Factored Force-Displacement curves of one bolt single-lap joints.

Figure 4. Effect of plate thickness on one bolt single-lap joints: Damage on: (a) S15E15T3,

(b) S15E15T6, (c) S15E15T9. (d) Factored Force-Displacement curves of S15E15T3 compared to S15E15T6 and S15E15T9.

Figure 5. Effect of joint eccentricity: Out-of-plane deformation of: (a) S15E15T6 and (b) S30E30G60T3. Fracture of: (c) S15E15T6, (d) DS15E15T6. (e) Factored force-displacement curves of DS15E15T6 compared to S15E15T6.

Figure 6. Effect of geometrical parameters in two-bolt single-lap configuration: Damages on:

(a) S25E30P30T6, (b) S303E0P30T6, (c) S30E30G60T3. (d) Factored force-displacement curves of S25E30P30T6, S30E30P30T6 and S30E30G60T3.

Figure 7. FE analysis: (a) Typical 3DAS model, (b) Typical 3DA model. Postprocessing response: (c) net-section failure, (d) shear tear-out failure, (e) bearing failure

Figure 8. Typical force-displacement curves of the experimental compared to finite element models: (a) S15E15T3, (b) S25E25T6, (c) S30E30P30T6, (d) S30E30G60T3

Figure 9. Effect of plate thickness on the joint strength: (a) Typical failure mode,

(b) Relationship failure load-plate thickness.

Figure 10. (a) Effect of end-distance and side-distance on one bolt, (b) Effect of end-distance and side-distance on two-bolt in a column, (c) Effect of end-distance and side-distance on two-bolt in a row. 
723 List of Tables

724 Table 1. Geometric recommendations for aluminum bolted connection

725

Table 2. Aluminum tensile test results (coupons)

726 Table 3. Comparison between experimental and predicted results

727 Table 4. Comparison between experimental and FE results

728 Table 5. FE parametric results for one-bolt connections ( $t=6.35 \mathrm{~mm}$ and $d=12.7 \mathrm{~mm})$

729 Table 6. FE parametric results for two-bolt connections $(t=6.35 \mathrm{~mm}$ and $d=12.7 \mathrm{~mm})$

730 Table 7. Optimum parameters for one-bolt connections

731 Table 8. Optimum parameters for two-bolt in a column $(e=2 d)$

732 Table 9. Optimum parameters for two-bolt in row $(s=3 d)$

733 


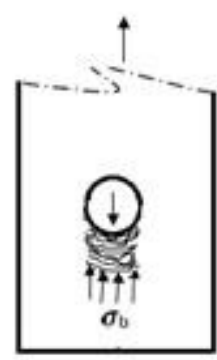

(a)

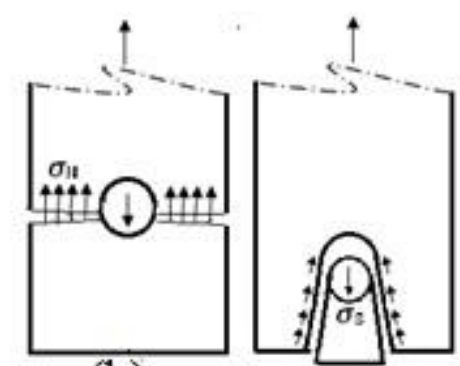

(b)

(c)

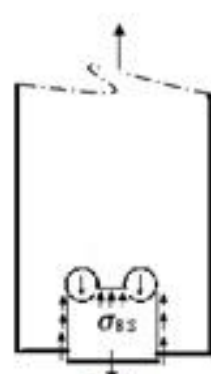

(d)

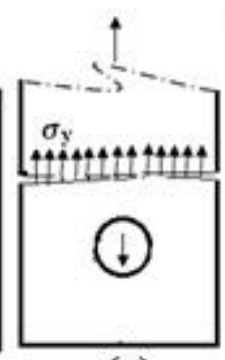

(e)

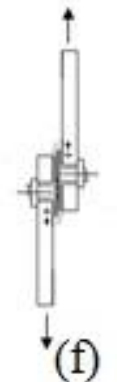

(f)

Figure 1. Failure modes: (a) Bearing, (b) net-section, (c) shear tear-out, (d) block737 

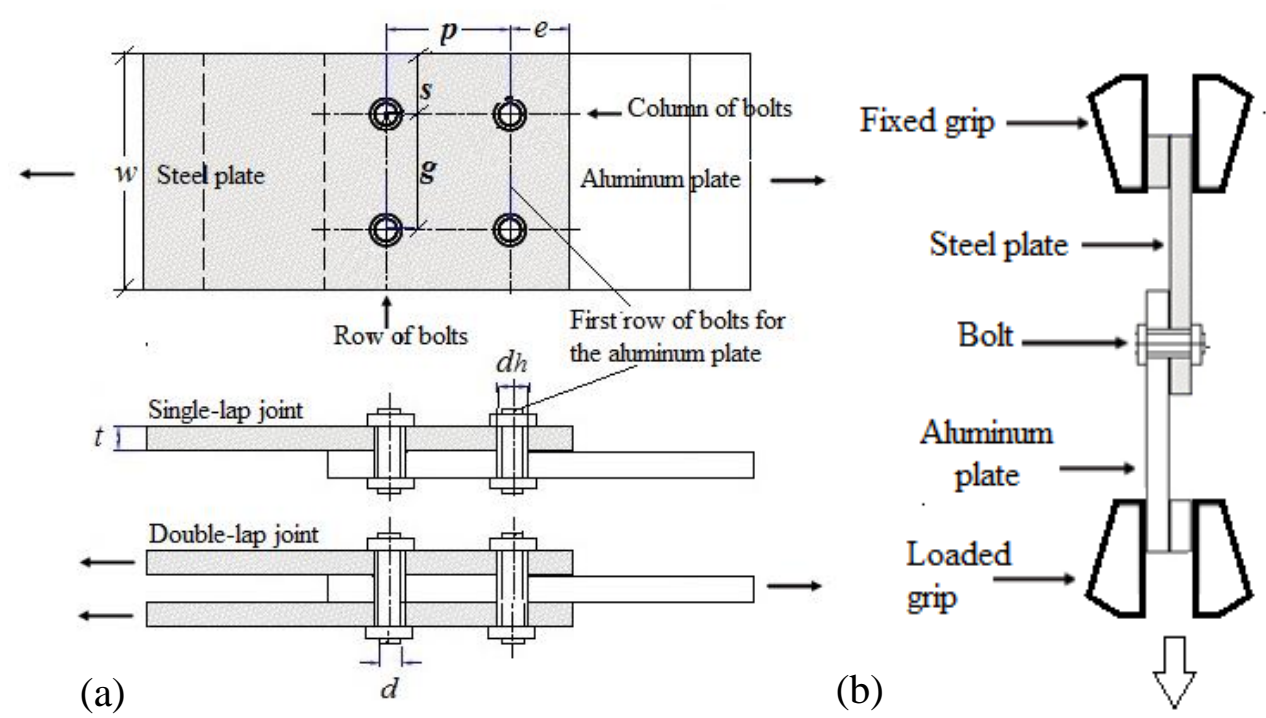

Figure 2. (a) Typical bolted joint in single-lap and double-lap arrangements, (b) Test set-up of aluminum to steel connection 


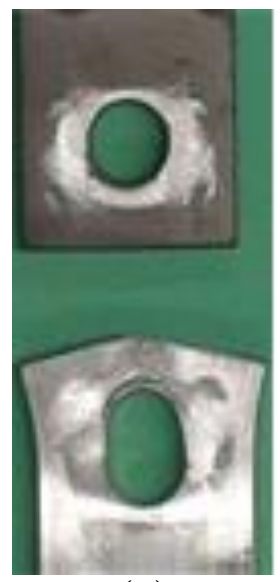

(a)

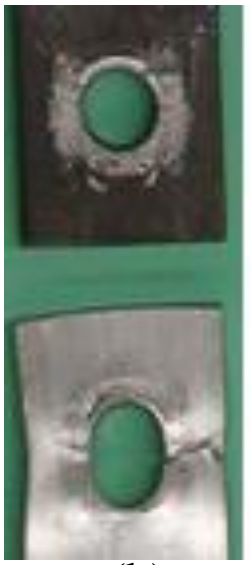

(b)

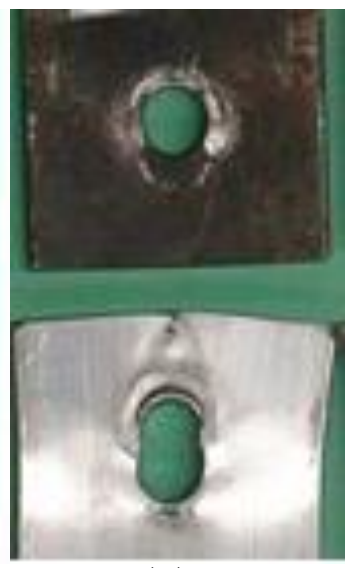

(c)

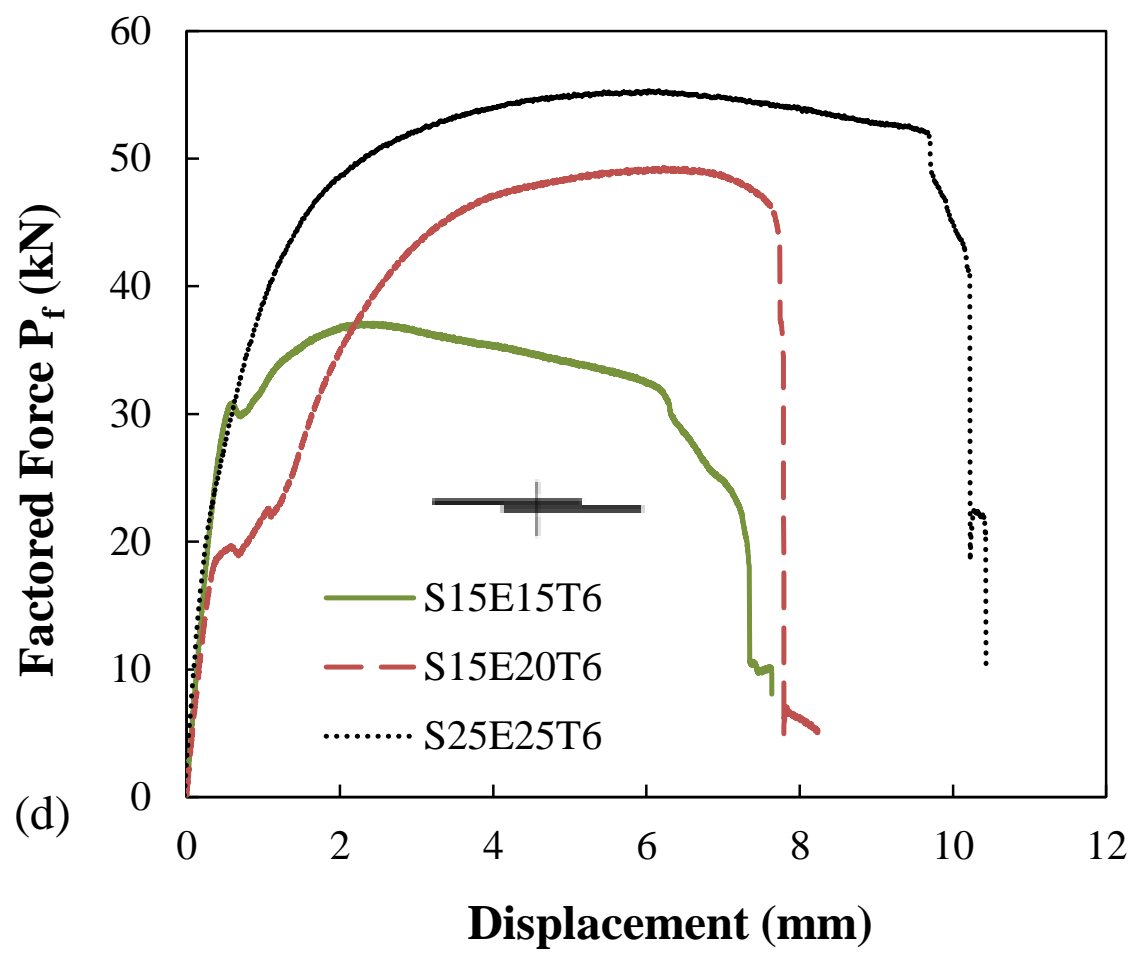

Figure 3. Effect of $s$ and $e$ on one bolt single-lap joints: Damage on: (a) S15E15T6, (b) S15E20T6, (c) S25E25T6, (d) Factored Force-Displacement curves of one bolt single-lap joints. 

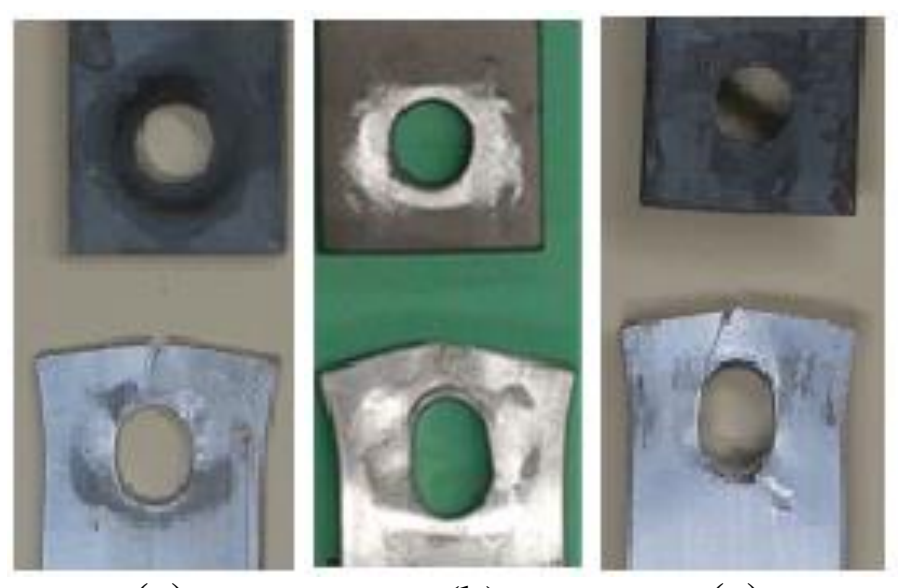

(a)

(b)

(c)

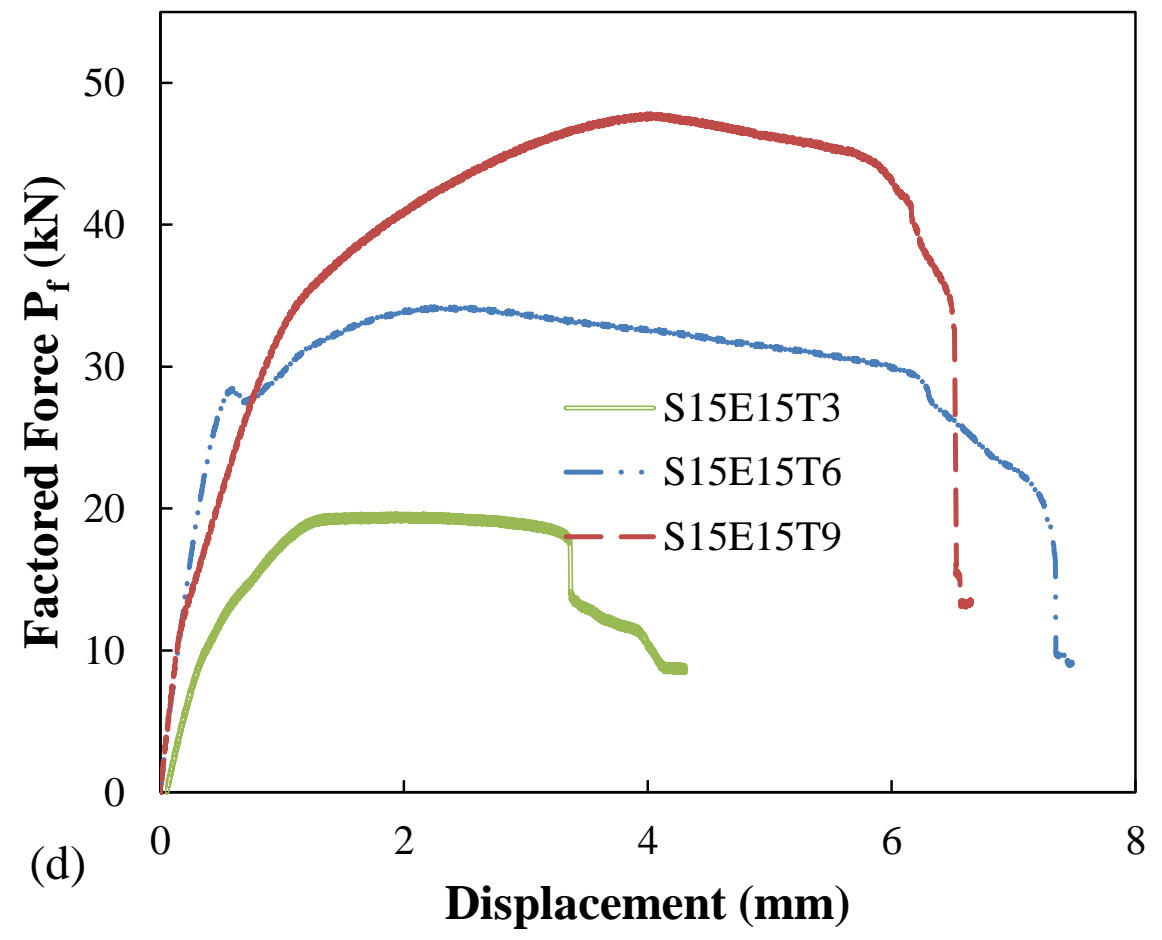

Figure 4. Effect of plate thickness on one bolt single-lap joints: Damage on: (a) S15E15T3; (b) S15E15T6; (c) S15E15T9, (d) Factored Force-Displacement curves 


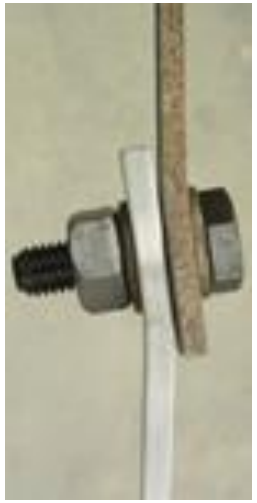

(a)

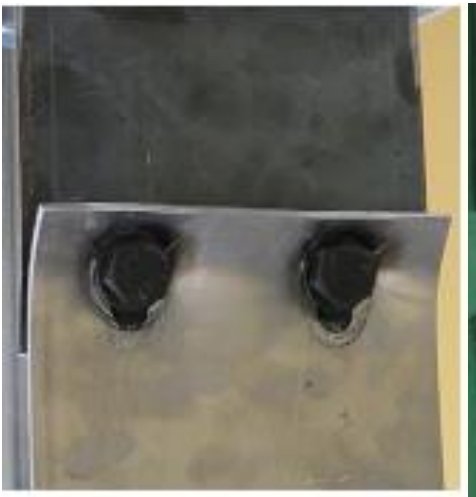

(b)

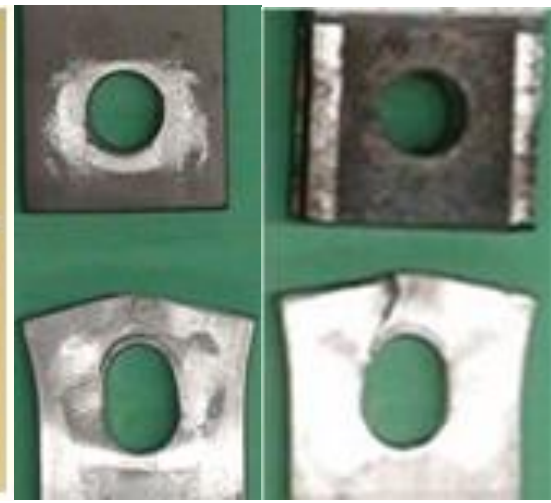

(c)

(d)

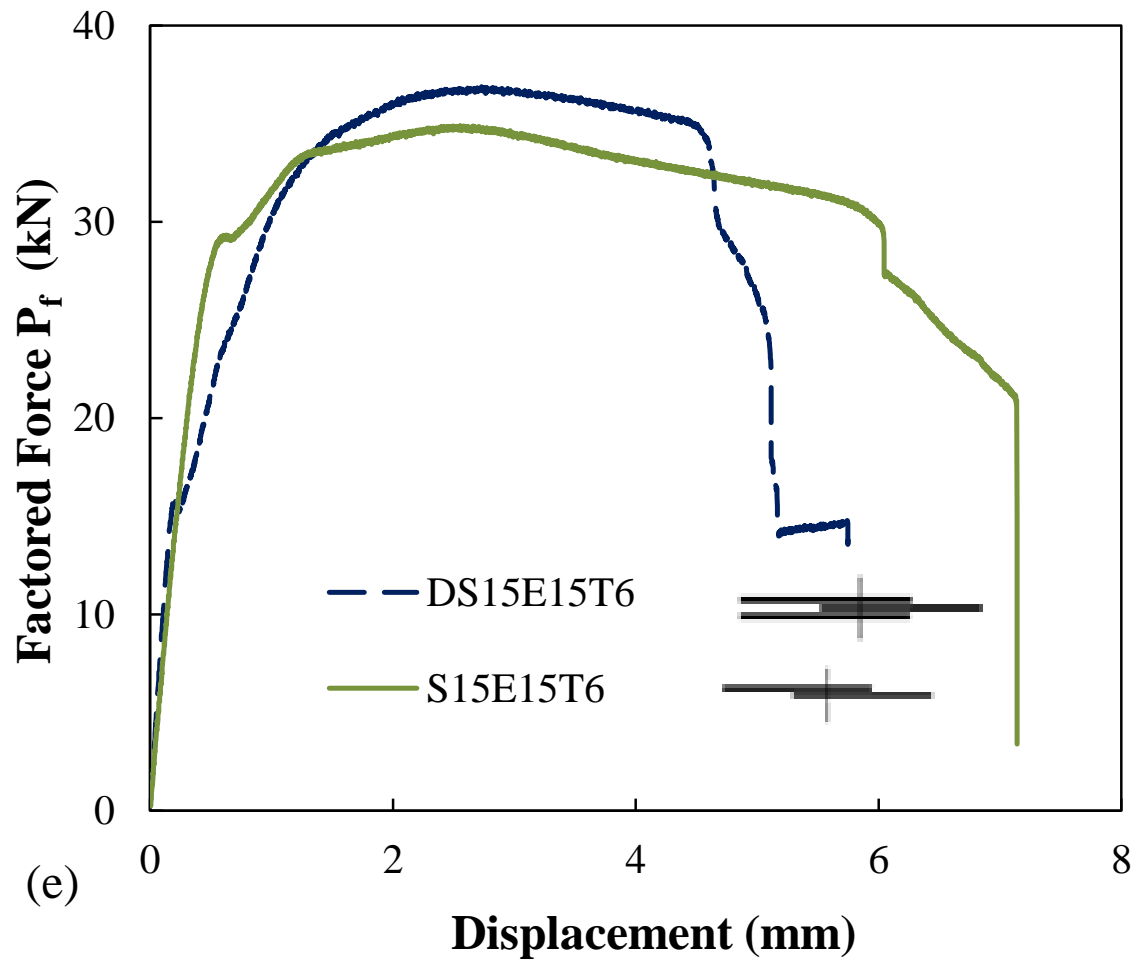

Figure 5. Effect of joint eccentricity: Out-of-plane deformation of (a) S15E15T6 and (b) S30E30G60T3. (c) Fracture of S15E15T6, (d) Fracture of DS15E15T6, (e) Factored forcedisplacement curves of DS15E15T6 compared to S15E15T6 


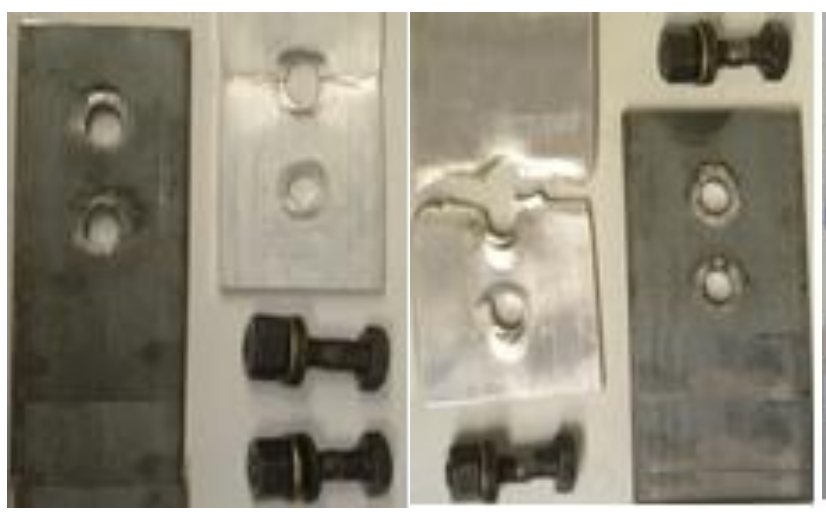

(a)

(b)

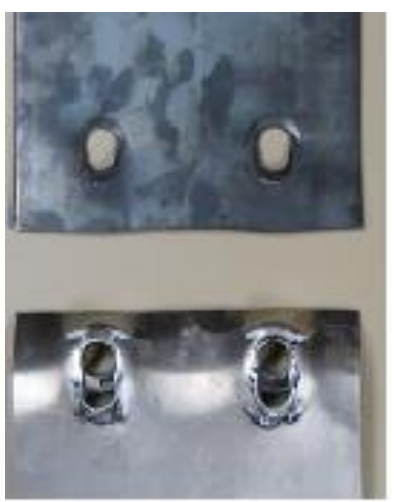

(c)

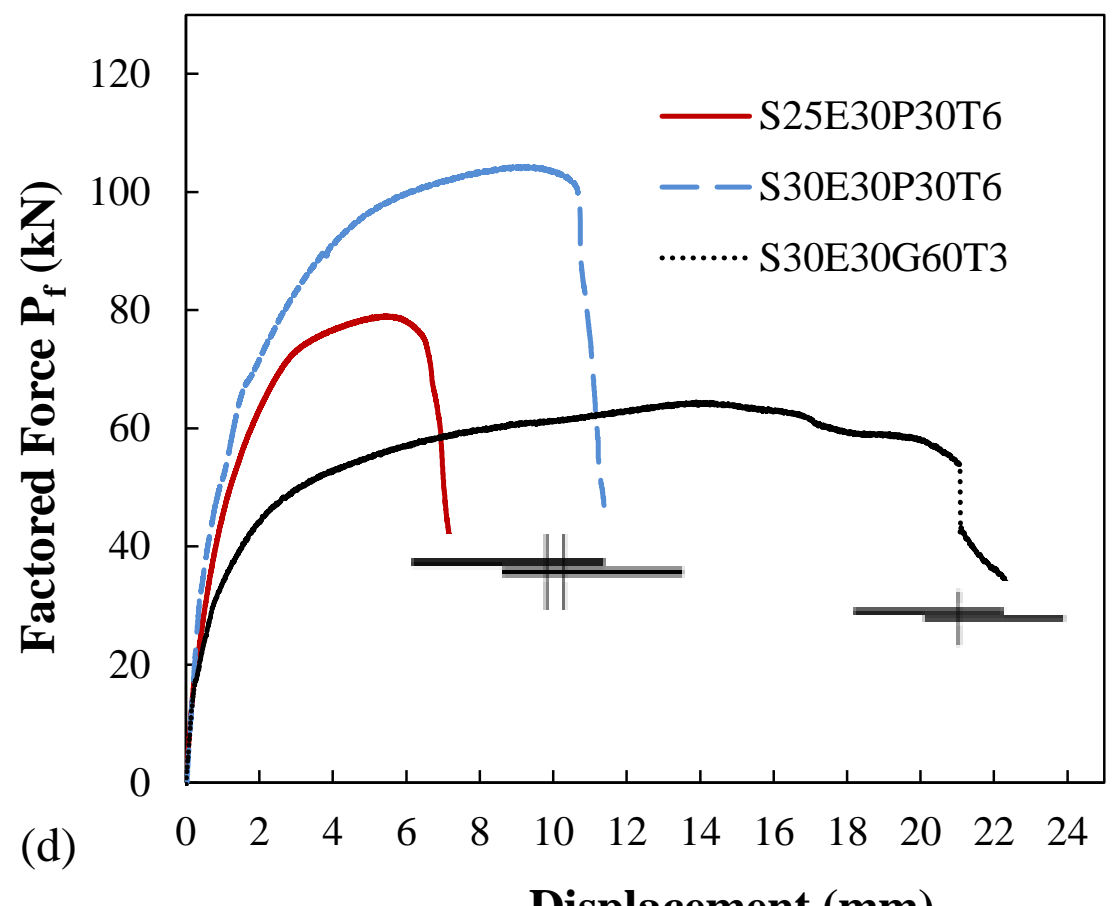

Figure 6. Effect of geometrical parameters in two-bolt single-lap configuration: Damages on 2 bolts joints: (a) S25E30P30T6; (b) S303E0P30T6; (c) S30E30G60T3, (d) Factored forcedisplacement curves of S30E30P30T6, S25E30P30T6 and S30E30G60T3 

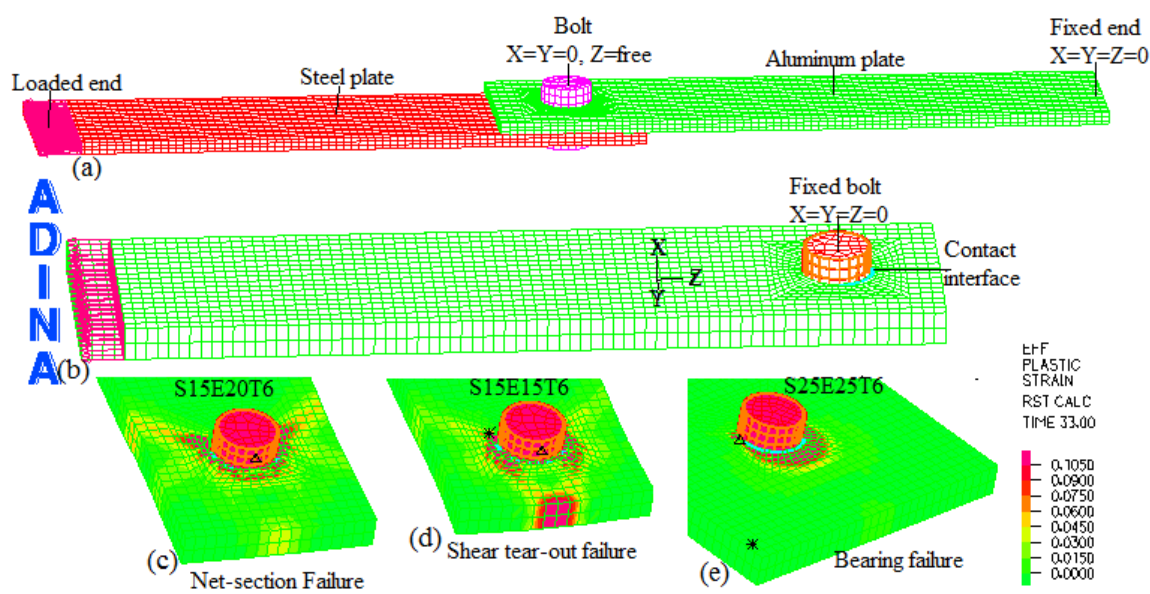

Figure 7. FE models: (a) Typical FE_3DAS model, (b) Typical FE_3DA model. Post-processing response: (c) Net-section failure, (d) Shear tear-out failure, (e) Bearing failure 


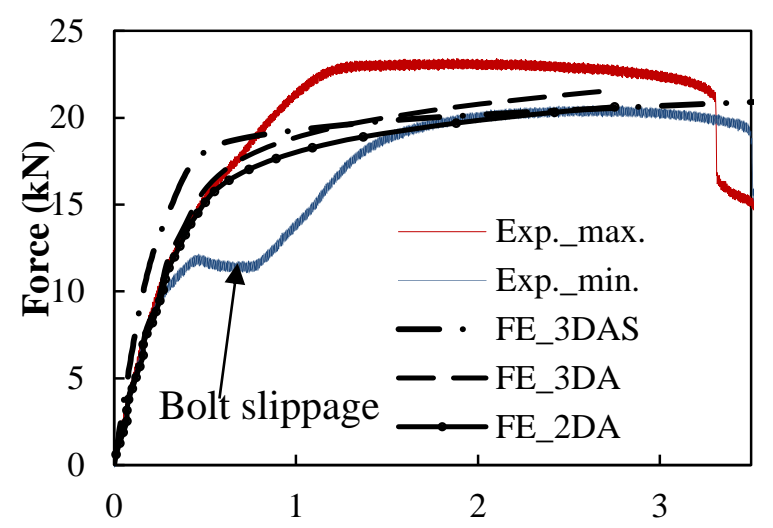

(a)

Displacement (mm)

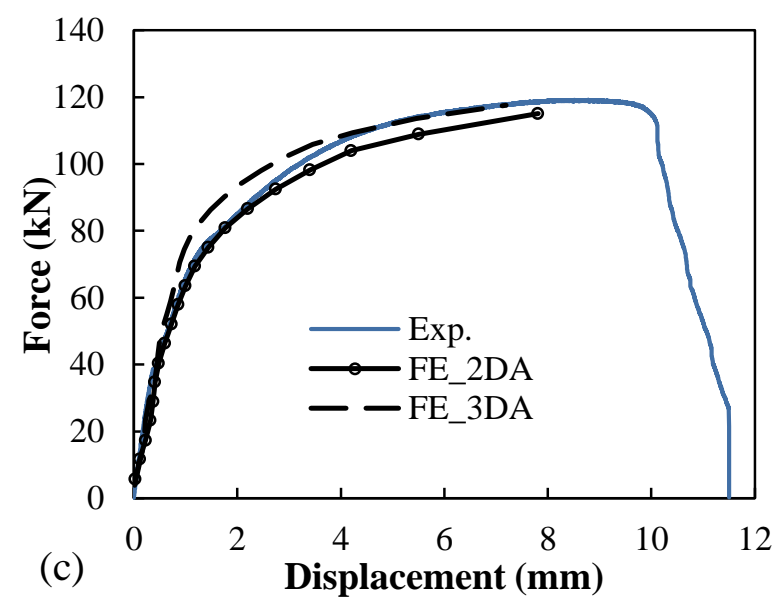

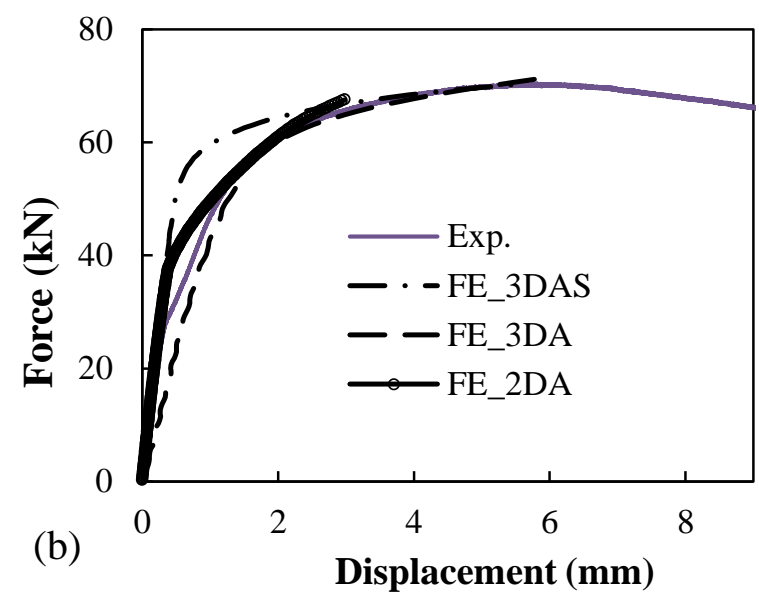

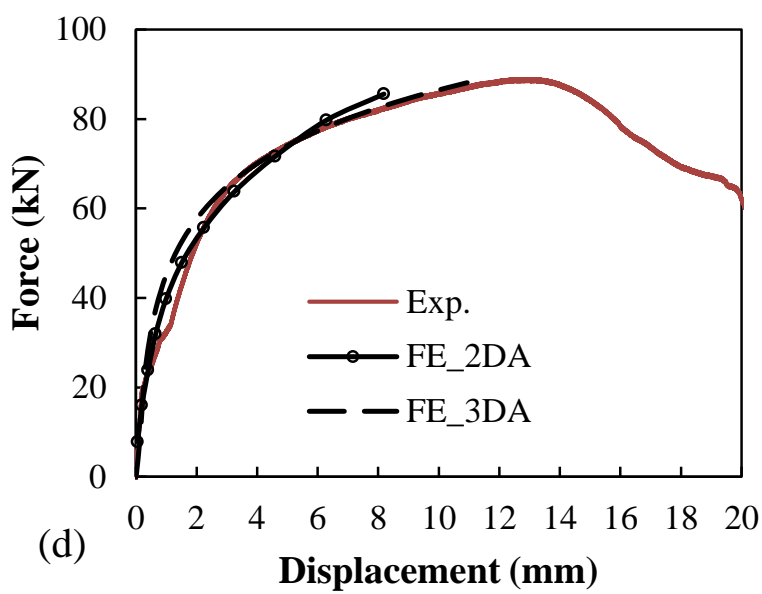

Figure 8. Typical force-displacement curves of the experimental compared to finite element models: (a) S15E15T3, (b) S25E25T6, (c) S30E30P30T6, (d) S30E30G60T3 
(a)
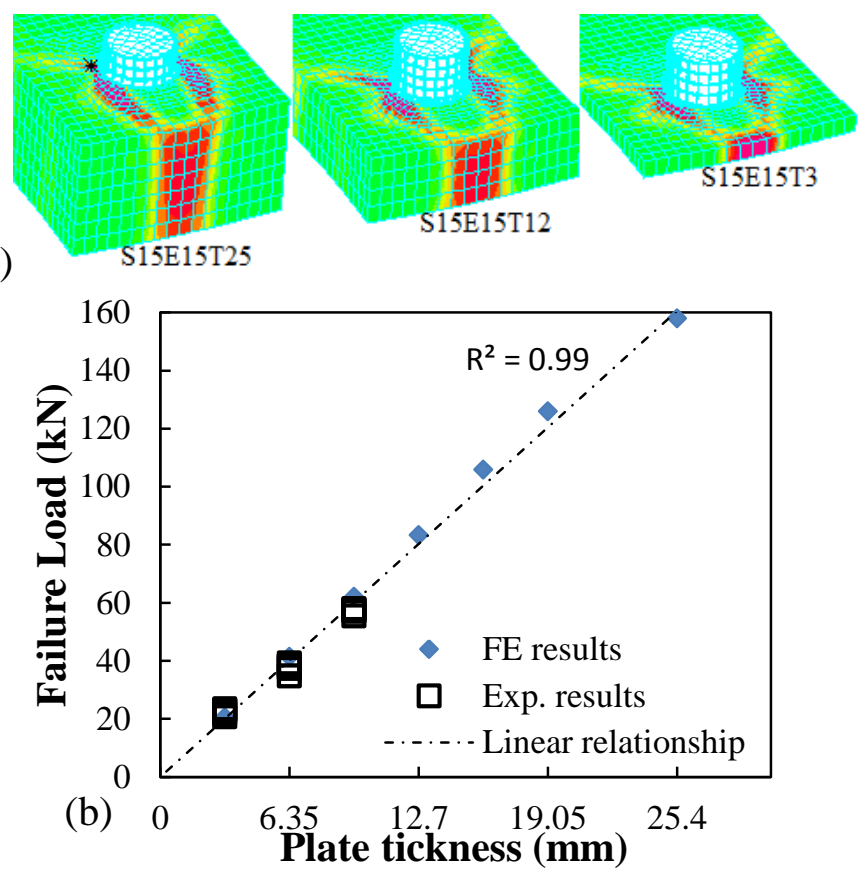

Figure 9. Effect of plate thickness on the joint strength: (a) failure modes, (b) Relationship Failure Load-Plate thickness

771 

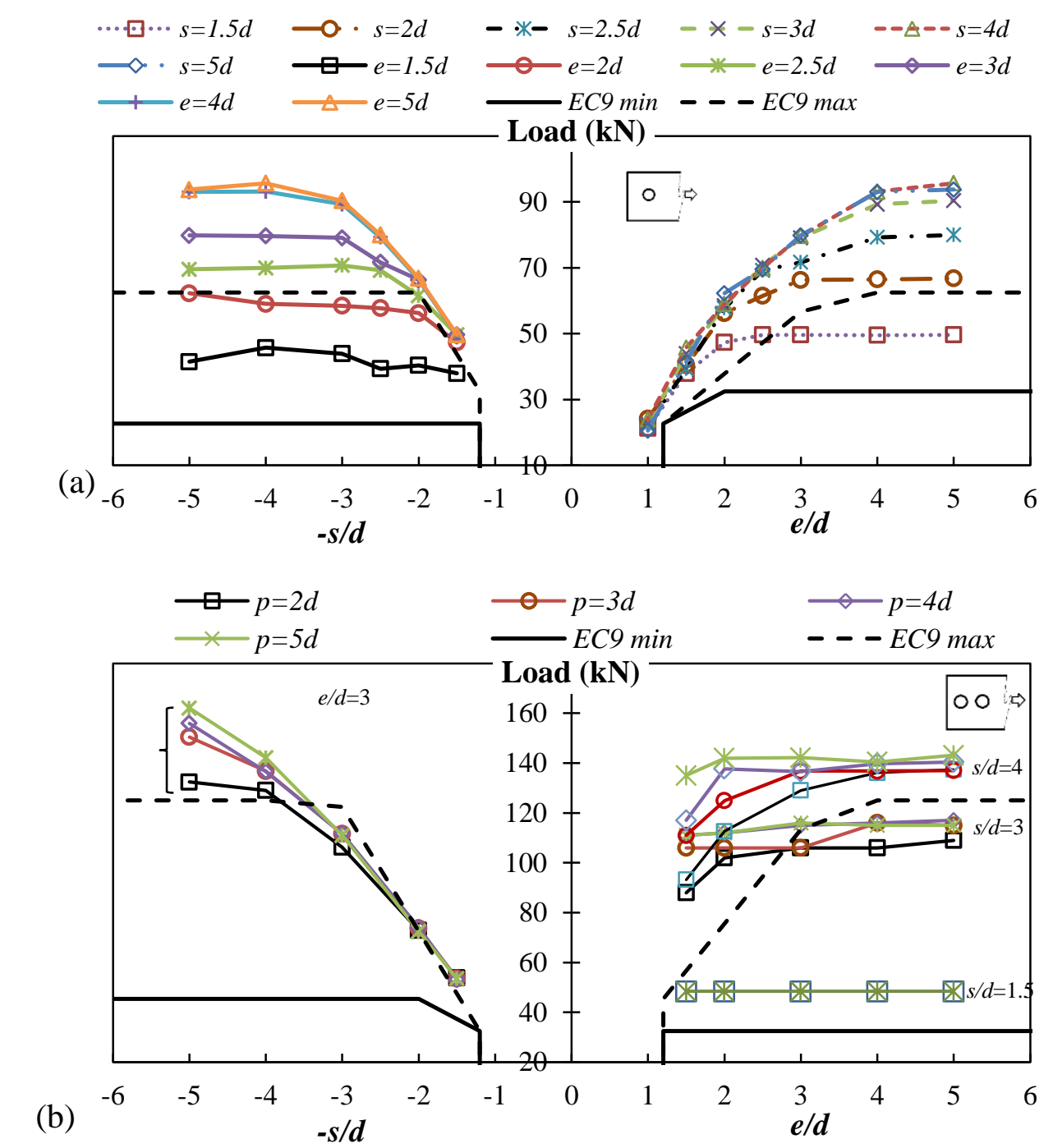

(b)

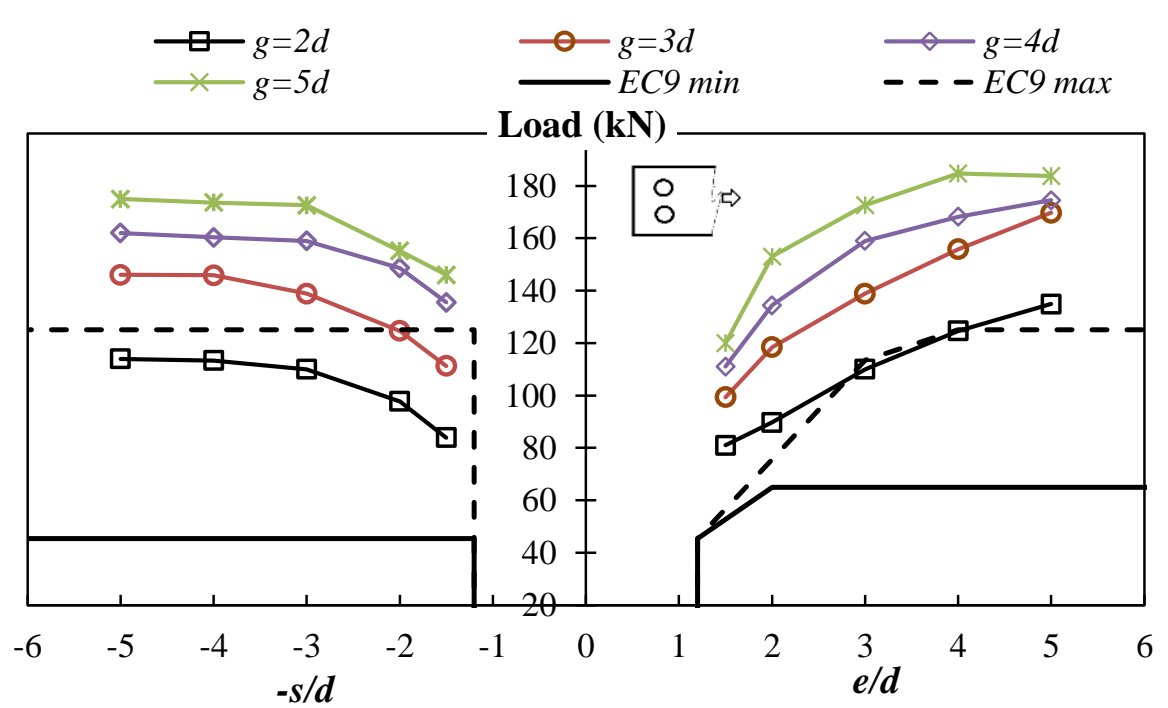

Figure 10. Effect of (a) end-distance and side-distance on one bolt, (b) end-distance and side-distance on 2-bolt in a column, (c) end-distance and side-distance on 2-bolt in a row 
775

776

Table 1. Geometric recommendations for aluminum bolted connection

\begin{tabular}{ccccccccc}
\hline \multirow{2}{*}{$\begin{array}{c}\text { Design } \\
\text { Codes }\end{array}$} & \multicolumn{2}{c}{$\begin{array}{c}\text { Pitch } \\
(\boldsymbol{p})\end{array}$} & \multicolumn{2}{c}{$\begin{array}{c}\text { Gage } \\
(\boldsymbol{g})\end{array}$} & \multicolumn{2}{c}{ End-distance $(\boldsymbol{e})$} & \multicolumn{2}{c}{ Side-distance $(\boldsymbol{s})$} \\
\cline { 2 - 9 } & Min. & Max. & Min. & Max. & Min. & Max. & Min. & Max. \\
\hline $\begin{array}{c}\text { CSA-S157 } \\
\text { [3] }\end{array}$ & $3 d$ & - & $2.5 d$ & - & $1.5 d$ & - & $1.25 d$ & - \\
\hline $\begin{array}{c}\text { AASHTO } \\
{[2]}\end{array}$ & $2.5 d$ & $17 t$ & $2.5 d$ & $17 t$ & $2 d_{h}$ & $\begin{array}{c}5.5 t \text { or } \\
90 \mathrm{~mm}\end{array}$ & $1.5 d_{h}$ & $\begin{array}{c}5.5 t \text { or } 90 \\
\mathrm{~mm}\end{array}$ \\
\hline EC9 [1] & $2.2 d$ & $\begin{array}{c}14 t \text { or } \\
200 \\
\mathrm{~mm}\end{array}$ & $2.4 d$ & $\begin{array}{c}14 t \text { or } \\
200 \\
\mathrm{~mm}\end{array}$ & $1.2 d$ & $\begin{array}{c}4 t+ \\
40 \mathrm{~mm}\end{array}$ & $1.2 d$ & $\begin{array}{c}4 t+ \\
40 \mathrm{~mm}\end{array}$ \\
\hline
\end{tabular}

777

778

779 
Table 2. Aluminum tensile test results (coupons)

\begin{tabular}{|c|c|c|c|c|c|c|}
\hline $\begin{array}{l}\text { Correspon } \\
\text { ding bolted } \\
\text { specimens }\end{array}$ & $\begin{array}{c}\text { Couponna } \\
\text { me }\end{array}$ & $\begin{array}{c}f_{\mathrm{u}} \\
(\mathrm{MPa})\end{array}$ & $\begin{array}{c}f_{0.2} \\
(\mathrm{MPa})\end{array}$ & $\begin{array}{l}\varepsilon_{f u} \\
(\%)\end{array}$ & $\begin{array}{l}\varepsilon_{0.2} \\
(\%)\end{array}$ & $\begin{array}{c}\mathrm{E} \\
(\mathrm{GPa})\end{array}$ \\
\hline \multirow{4}{*}{$\begin{array}{c}\text { Al-St } \\
\text { S15E15T3 }\end{array}$} & $\mathrm{Al}_{\mathrm{A}_{2} 1}$ & 310.4 & 280.5 & - & 0.54 & 78.4 \\
\hline & $\mathrm{Al}_{\mathrm{A} \_2}$ & 309.1 & 277.5 & 7.7 & 0.52 & 69.3 \\
\hline & $\mathrm{Al}_{\mathrm{A} 3}$ & 310.2 & 279.6 & 9.6 & 0.53 & 67.5 \\
\hline & Aver. & 309.9 & 279.2 & 8.7 & 0.53 & 71.7 \\
\hline \multirow{3}{*}{$\begin{array}{c}\text { Al-St } \\
\text { S15E15T6 }\end{array}$} & $\mathrm{Al}_{\mathrm{B}_{1} 1}$ & 305.1 & 279.0 & 8.0 & 0.43 & 69.4 \\
\hline & $\mathrm{Al}_{\mathrm{B} \_2}$ & 300.1 & - & - & - & - \\
\hline & Aver. & 302.6 & - & - & - & - \\
\hline \multirow{4}{*}{$\begin{array}{c}\text { Al-St } \\
\text { S15E15T9 }\end{array}$} & $\overline{\mathrm{Al}_{\mathrm{C}_{-} 1}}$ & 312.2 & 293.3 & 7.8 & 0.62 & 64.7 \\
\hline & $\mathrm{Al}_{\mathrm{C} \_2}$ & 313.7 & 294.3 & 8.0 & 0.6 & 70.9 \\
\hline & $\mathrm{Al}_{\mathrm{C}_{3} 3}$ & 311.3 & 292.9 & 7.8 & 0.61 & 73.0 \\
\hline & Aver. & 312.4 & 293.5 & 7.9 & 0.61 & 69.5 \\
\hline \multirow{3}{*}{$\begin{array}{c}\text { Al-St } \\
\text { S15E20T6 }\end{array}$} & $\mathrm{Al}_{\mathrm{B}_{-} 1}$ & 305.1 & 279.0 & 8.0 & 0.43 & 69.4 \\
\hline & $\mathrm{Al}_{\mathrm{B} \_2}$ & 300.1 & - & - & - & - \\
\hline & Aver. & 302.6 & - & - & - & - \\
\hline \multirow{3}{*}{$\begin{array}{c}\text { Al-St } \\
\text { S25E25T6 }\end{array}$} & $\mathrm{Al}_{\mathrm{D}_{-} 1}$ & 330.4 & 302.7 & 9.0 & 0.47 & 75.5 \\
\hline & $\mathrm{Al}_{\mathrm{D} \_2}$ & 331.1 & 302.6 & 10.0 & 0.47 & 71.4 \\
\hline & Aver. & 330.7 & 302.7 & 9.5 & 0.47 & 73.4 \\
\hline St-Al.-St & $\mathrm{Al}_{\mathrm{E} \_1}$ & 330.1 & 300.6 & 9.1 & 0.46 & 69.6 \\
\hline \multirow[t]{2}{*}{ DS15E15T6 } & $\mathrm{Al}_{\mathrm{E} \_2}$ & 331.1 & 300.2 & 9.5 & 0.46 & 70.6 \\
\hline & Aver. & 330.6 & 300.4 & 9.3 & 0.46 & 70.1 \\
\hline $\mathrm{Al}-\mathrm{St}$ & $\mathrm{Al}_{\mathrm{F}_{1} 1}$ & 301.8 & 273.0 & 9.5 & 0.42 & 68.9 \\
\hline \multirow{2}{*}{$\begin{array}{c}\text { S25E30P30 } \\
\text { T6 }\end{array}$} & $\mathrm{Al}_{\mathrm{F}_{-} 2}$ & 297.8 & 264.5 & 9.1 & 0.41 & 70.0 \\
\hline & Aver. & 299.8 & 268.8 & 9.3 & 0.42 & 69.4 \\
\hline \multirow{3}{*}{$\begin{array}{c}\text { Al-St } \\
\text { S30E30P30 } \\
\text { T6 }\end{array}$} & $\mathrm{Al}_{\mathrm{G}_{-} 1}$ & 310.6 & 273.0 & 8.6 & 0.42 & 63.1 \\
\hline & $\mathrm{Al}_{\mathrm{G}_{-} 2}$ & 312.8 & 275.0 & 10.2 & 0.42 & 71.3 \\
\hline & Aver. & 311.7 & 274.0 & 9.4 & 0.42 & 67.2 \\
\hline \multirow{4}{*}{$\begin{array}{c}\text { Al-St } \\
\text { S30E30G6 } \\
\text { T3 }\end{array}$} & $\mathrm{Al}_{\mathrm{H} \_1}$ & 359.5 & 318.0 & 10.3 & 0.53 & 66.3 \\
\hline & $\mathrm{Al}_{\mathrm{H} \_2}$ & 358.1 & 315.0 & 9.3 & 0.5 & 76.6 \\
\hline & $\mathrm{Al}_{\mathrm{H}_{-} 3}$ & 351.5 & 309.8 & 12 & 0.52 & 70.1 \\
\hline & Aver. & 356.4 & 314.3 & 10.5 & 0.52 & 71.0 \\
\hline \multirow{3}{*}{$\begin{array}{l}\text { Design } \\
\text { references }\end{array}$} & CSA-S157 & 260 & 240 & - & - & 70 \\
\hline & AASHTO & 290 & 240 & 10 & - & 70 \\
\hline & EC9 & 290 & 240 & - & - & 70 \\
\hline
\end{tabular}


783

Table 3. Experimental test results compared to predicted results

\begin{tabular}{|c|c|c|c|c|c|c|c|c|c|c|c|c|c|}
\hline \multirow{3}{*}{ Test names } & \multicolumn{4}{|c|}{ Experimental (aver . load) } & \multicolumn{3}{|c|}{ EC9 (2007) } & \multicolumn{3}{|c|}{ AASHTO (2007) } & \multicolumn{3}{|c|}{ CSA-S157 (2007) } \\
\hline & 1 & 2 & 3 & 4 & 5 & 6 & 7 & 8 & 9 & 10 & 11 & 12 & 13 \\
\hline & $\begin{array}{l}\mathrm{P}_{\exp } \\
(\mathrm{kN})\end{array}$ & $\begin{array}{l}\text { Std. } \\
\text { dev. }\end{array}$ & $\begin{array}{c}\mathrm{P}_{\mathrm{f}} \\
(\mathrm{kN})\end{array}$ & FM & $\begin{array}{c}P_{n} \\
(k N)\end{array}$ & $1 / 5$ & FM & $\begin{array}{c}\mathrm{P}_{\mathrm{n}} \\
(\mathrm{kN})\end{array}$ & $1 / 8$ & FM & $\begin{array}{c}P_{n} \\
(k N)\end{array}$ & $1 / 11$ & FM \\
\hline S15E15T3 & 22.4 & 1.09 & 18.8 & $S$ & 14.2 & 1.58 & B & 14.0 & 1.60 & B & 18.7 & 1.20 & $S$ \\
\hline S15E15T6 & 39.6 & 0.66 & 33.8 & S & 27.7 & 1.43 & B & 28.0 & 1.41 & B & 36.6 & 1.08 & S \\
\hline S15E15T9 & 57.1 & 1.04 & 47.5 & S & 43.1 & 1.32 & B & 44.1 & 1.29 & B & 56.7 & 1.01 & $S$ \\
\hline S15E20T6 & 52.6 & 0.56 & 44.8 & $\mathrm{~N}$ & 36.9 & 1.43 & B & 37.4 & 1.41 & B & 46.3 & 1.14 & $\mathrm{~N}$ \\
\hline S25E25T6 & 69.4 & 0.68 & 54.4 & $\mathrm{~B}$ & 50.4 & 1.38 & $\mathrm{~B}$ & 40.6 & 1.71 & $\mathrm{~B}$ & 53.3 & 1.30 & $\mathrm{~B}$ \\
\hline DS15E15T6 & 45.6 & 1.51 & 35.9 & $\mathrm{~S}$ & 30.2 & 1.51 & $\mathrm{~B}$ & 30.1 & 1.51 & $\mathrm{~B}$ & 40.0 & 1.14 & $\mathrm{~S}$ \\
\hline S25E30P30T6 & 95.0 & 0.83 & 79.3 & $\mathrm{~N}$ & 79.5 & 1.19 & B & 72.0 & 1.32 & B & 96.7 & 0.98 & $\mathrm{~N}$ \\
\hline S30E30P30T6 & 120.2 & 0.63 & 104.1 & $\mathrm{~N}$ & 82.7 & 1.45 & B & 73.4 & 1.64 & B & 100.3 & 1.20 & B \\
\hline S30E30G60T3 & 86.84 & 1.13 & 63.4 & $\mathrm{~B}$ & 65.2 & 1.33 & $\mathrm{~B}$ & 42.08 & 2.06 & $\mathrm{~B}$ & 57.5 & 1.51 & $\mathrm{~B}$ \\
\hline
\end{tabular}

784

785

786

FM: Failure mode, N: net-section failure; B: bearing failure, $\mathrm{S}$ : shear tear-out failure

787

Table 4. Experimental versus FE predicted results

\begin{tabular}{|c|c|c|c|c|c|c|c|}
\hline & $\begin{array}{l}\mathrm{P}_{\exp } \\
(\mathrm{kN})\end{array}$ & $\begin{array}{l}\text { Exp. } \\
\text { FM } \\
\end{array}$ & $\begin{array}{c}3 \mathrm{D} \mathrm{P}_{\mathrm{FE}} \\
(\mathrm{kN})\end{array}$ & $\begin{array}{l}\mathrm{FE} \\
\mathrm{FM} \\
\end{array}$ & $\mathrm{P}_{\text {exp }} / \mathrm{P}_{3 \mathrm{DFE}}$ & $\begin{array}{c}2 \mathrm{D} \mathrm{P}_{\mathrm{FE}} \\
(\mathrm{kN})\end{array}$ & $\mathrm{P}_{\text {exp }} / \mathrm{P}_{2 \mathrm{DFE}}$ \\
\hline S15E15T3 & 22.4 & $\mathrm{~S}$ & 21.6 & $\mathrm{~S}$ & 1.04 & 20.6 & 1.09 \\
\hline S15E15T6 & 39.6 & $\mathrm{~S}$ & 39.7 & $\mathrm{~S}$ & 0.99 & 38.0 & 1.04 \\
\hline S15E15T9 & 57.1 & $\mathrm{~S}$ & 56.4 & $\mathrm{~S}$ & 1.01 & 58.7 & 0.97 \\
\hline S15E20T6 & 52.6 & $\mathrm{~N}$ & 52.9 & $\mathrm{~N}$ & 0.99 & 47.3 & 1.11 \\
\hline S25E25T6 & 69.4 & B & 71.5 & B & 0.97 & 69.8 & 0.99 \\
\hline DS15E15T6 & 45.6 & $S$ & 42.3 & $S$ & 1.08 & 41.4 & 1.10 \\
\hline S25E30P30T6 & 95.0 & $\mathrm{~N}$ & 98.3 & $\mathrm{~N}$ & 0.97 & 102.8 & 0.92 \\
\hline S30E30P30T6 & 120.2 & $\mathrm{~N}$ & 117.6 & $\mathrm{~N}$ & 1.02 & 115.1 & 1.04 \\
\hline \multirow[t]{2}{*}{ S30E30G60T3 } & 86.84 & B & 88.3 & B & 0.98 & 85.6 & 1.01 \\
\hline & & & dard dev & $\begin{array}{l}\text { rage } \\
\text { ation }\end{array}$ & $\begin{array}{l}1.01 \\
0.04\end{array}$ & & $\begin{array}{l}1.03 \\
0.06\end{array}$ \\
\hline
\end{tabular}

788 
Table 5. FE results for one-bolt connection $(t=6.35 \mathrm{~mm}$ and $d=12.7 \mathrm{~mm})$

\begin{tabular}{|c|c|c|c|c|c|}
\hline \multicolumn{6}{|c|}{ One-bolt (1X1) failure load $(\mathrm{kN}) /$ failure mode } \\
\hline & & & $e / d$ & & \\
\hline$s / d$ & 1.5 & 2 & 3 & 4 & 5 \\
\hline 1.5 & $41.4 / \mathrm{S}$ & $47.3 / \mathrm{N}$ & $49.6 / \mathrm{N}$ & $49.5 / \mathrm{N}$ & $49.6 / \mathrm{N}$ \\
\hline 2 & $45.7 / \mathrm{S}$ & $56.2 / \mathrm{S}$ & $66.3 / \mathrm{N}$ & $66.5 / \mathrm{N}$ & $66.8 / \mathrm{N}$ \\
\hline 3 & $43.9 / \mathrm{S}$ & $58.5 / \mathrm{S}$ & 79.1/B & $89.3 / \mathrm{B}$ & $90.4 / \mathrm{B}$ \\
\hline 4 & $39.3 / \mathrm{S}$ & $59.0 / \mathrm{S}$ & 79.7/B & 93.1/B & $95.7 / \mathrm{B}$ \\
\hline 5 & $40.4 / \mathrm{S}$ & $62.2 / \mathrm{S}$ & $79.8 / \mathrm{B}$ & 93.0/B & 93.8/B \\
\hline
\end{tabular}

Table 6. FE results for two-bolt connection $(t=6.35 \mathrm{~mm}$ and $d=12.7 \mathrm{~mm})$

\begin{tabular}{|c|c|c|c|c|c|c|c|c|c|c|c|}
\hline \multicolumn{6}{|c|}{ Two-bolt in a column (1X2) FL (kN)/FM } & \multicolumn{6}{|c|}{ Two-bolt in a row $(2 \mathrm{X} 1) \mathrm{FL}(\mathrm{kN}) / \mathrm{FM}$} \\
\hline \multicolumn{6}{|c|}{$p / d$} & \multirow[b]{2}{*}{$s / d$} & \multicolumn{5}{|c|}{$g / d$} \\
\hline$s / d$ & $e / d$ & 2 & 3 & 4 & 5 & & $e / d$ & 2 & 3 & 4 & 5 \\
\hline \multirow{5}{*}{1.5} & 1.5 & $48.4 / \mathrm{N}$ & $48.4 / \mathrm{N}$ & $48.4 / \mathrm{N}$ & $48.4 / \mathrm{N}$ & & 1.5 & $69.0 / \mathrm{S}$ & $103 / \mathrm{S}$ & $101 / \mathrm{S}$ & 96.7/S \\
\hline & 2 & $48.4 / \mathrm{N}$ & $48.4 / \mathrm{N}$ & $48.4 / \mathrm{N}$ & $48.4 / \mathrm{N}$ & \multirow{4}{*}{1.5} & 2 & $79.1 / \mathrm{N}$ & $109 \mathrm{~N}$ & $130 / \mathrm{K}$ & $133 / \mathrm{K}$ \\
\hline & 3 & $48.4 / \mathrm{N}$ & $48.4 / \mathrm{N}$ & $48.4 / \mathrm{N}$ & $48.4 / \mathrm{N}$ & & 3 & $83.9 / \mathrm{N}$ & $111 / \mathrm{N}$ & $136 / K$ & $152 / \mathrm{K}$ \\
\hline & 4 & $48.4 / \mathrm{N}$ & $48.4 / \mathrm{N}$ & $48.4 / \mathrm{N}$ & $48.4 / \mathrm{N}$ & & 4 & $84.9 / \mathrm{N}$ & $112 / \mathrm{N}$ & $140 / \mathrm{N}$ & $148 / \mathrm{N}$ \\
\hline & 5 & $48.4 / \mathrm{N}$ & $48.4 / \mathrm{N}$ & $48.4 / \mathrm{N}$ & $48.4 / \mathrm{N}$ & & 5 & $85.7 / \mathrm{N}$ & $111 / \mathrm{N}$ & $140 / \mathrm{N}$ & $160 / \mathrm{N}$ \\
\hline \multirow{5}{*}{2} & 1.5 & $71.5 / \mathrm{N}$ & $73.0 / \mathrm{N}$ & $73.0 / \mathrm{N}$ & $73.0 / \mathrm{N}$ & \multirow{5}{*}{2} & 1.5 & $76.5 / \mathrm{S}$ & $114 / \mathrm{S}$ & $109 / \mathrm{S}$ & $105 / \mathrm{S}$ \\
\hline & 2 & $72.4 / \mathrm{N}$ & $73.5 / \mathrm{N}$ & $72.7 / \mathrm{N}$ & $72.1 / \mathrm{N}$ & & 2 & $75.9 / \mathrm{K}$ & $108 / \mathrm{K}$ & 123/B & $122 / \mathrm{B}$ \\
\hline & 3 & $72.9 / \mathrm{N}$ & $73.8 / \mathrm{N}$ & $74.0 / \mathrm{N}$ & $72.4 / \mathrm{N}$ & & 3 & $91.7 / \mathrm{K}$ & $125 / \mathrm{K}$ & 145/B & $155 / \mathrm{B}$ \\
\hline & 4 & $73.2 / \mathrm{N}$ & $73.7 / \mathrm{N}$ & $72.9 / \mathrm{N}$ & $72.8 / \mathrm{N}$ & & 4 & $91.2 / \mathrm{K}$ & $126 / \mathrm{K}$ & 148/B & 168/B \\
\hline & 5 & $73.0 / \mathrm{N}$ & $73.5 / \mathrm{N}$ & $72.7 / \mathrm{N}$ & $72.2 / \mathrm{N}$ & & 5 & $92.0 / \mathrm{K}$ & $128 / \mathrm{K}$ & 147/B & 168/B \\
\hline \multirow{5}{*}{3} & 1.5 & $88 / \mathrm{N}$ & $106 / \mathrm{N}$ & $111 / \mathrm{N}$ & $111 / \mathrm{N}$ & \multirow{5}{*}{3} & 1.5 & $81.0 / \mathrm{S}$ & $99.3 / \mathrm{S}$ & $111 / \mathrm{S}$ & $120 / \mathrm{S}$ \\
\hline & 2 & $102 / \mathrm{N}$ & $106 / \mathrm{N}$ & $112 / \mathrm{N}$ & $112 / \mathrm{N}$ & & 2 & $89.7 / \mathrm{K}$ & $118 / \mathrm{K}$ & 134/B & $153 / \mathrm{B}$ \\
\hline & 3 & $106 / \mathrm{N}$ & $115 / \mathrm{N}$ & $115 / \mathrm{N}$ & $116 / \mathrm{N}$ & & 3 & $110 / \mathrm{K}$ & 139/K & 159/B & $173 / \mathrm{B}$ \\
\hline & 4 & $106 / \mathrm{N}$ & $116 / \mathrm{N}$ & $116 / \mathrm{N}$ & $115 / \mathrm{N}$ & & 4 & $125 / \mathrm{K}$ & $156 / \mathrm{K}$ & 168/B & $185 / \mathrm{B}$ \\
\hline & 5 & $109 / \mathrm{N}$ & $115 / \mathrm{N}$ & $117 / \mathrm{N}$ & $115 / \mathrm{N}$ & & 5 & $135 / \mathrm{K}$ & $170 / \mathrm{K}$ & 175/B & 184/B \\
\hline \multirow{5}{*}{4} & 1.5 & 93.2/B & 111/B & 117/B & $135 / \mathrm{B}$ & \multirow{5}{*}{4} & 1.5 & $85.6 / \mathrm{S}$ & $112 / \mathrm{S}$ & $113 / \mathrm{S}$ & $115 / \mathrm{S}$ \\
\hline & 2 & 113/B & $125 / \mathrm{B}$ & 138/B & $142 / \mathrm{B}$ & & 2 & $87.2 / \mathrm{K}$ & $128 / \mathrm{K}$ & 139/B & 133/B \\
\hline & 3 & 129/B & 137/B & 137/B & 142/B & & 3 & $113 / \mathrm{K}$ & $146 / K$ & 160/B & 174/B \\
\hline & 4 & 136/B & 137/B & 140/B & 141/B & & 4 & $118 / \mathrm{K}$ & $154 / K$ & 185/B & 177/B \\
\hline & 5 & 137/B & 137/B & 141/B & 143/B & & 5 & $123 / \mathrm{K}$ & $166 / K$ & 189/B & $172 / \mathrm{B}$ \\
\hline \multirow{5}{*}{5} & 1.5 & 90.7/B & 105/B & $117 / \mathrm{B}$ & $115 / \mathrm{B}$ & \multirow{5}{*}{5} & 1.5 & $85 / \mathrm{S}$ & $115 / \mathrm{S}$ & $114 / \mathrm{S}$ & $117 / \mathrm{S}$ \\
\hline & 2 & 112/B & 133/B & 143/B & 164/B & & 2 & $81.7 / \mathrm{K}$ & $115 / \mathrm{K}$ & 130/B & $127 / \mathrm{B}$ \\
\hline & 3 & 132/B & 151/B & $156 / \mathrm{B}$ & 162/B & & 3 & $119 / \mathrm{K}$ & $146 / \mathrm{K}$ & 162/B & 174/B \\
\hline & 4 & 154/B & 158/B & $165 / \mathrm{B}$ & 180/B & & 4 & $128 / \mathrm{K}$ & $158 / \mathrm{K}$ & 177/B & 176/B \\
\hline & 5 & 151/B & 167/B & 165/B & 162/B & & 5 & $133 / \mathrm{K}$ & $164 / \mathrm{K}$ & 180/B & $185 / \mathrm{B}$ \\
\hline
\end{tabular}


Table 7. Optimum parameters for one-bolt connection

\begin{tabular}{cccccccccc}
\hline Bolt & $t$ & \multicolumn{2}{c}{$d=12.7 \mathrm{~mm}$} & \multicolumn{2}{c}{$d=15.88 \mathrm{~mm}$} & \multicolumn{2}{c}{$d=19.05 \mathrm{~mm}$} & \multicolumn{2}{c}{$d=25.4 \mathrm{~mm}$} \\
\cline { 2 - 10 } grade & $(\mathrm{mm})$ & $e / d$ & $s / d$ & $e / d$ & $s / d$ & $e / d$ & $s / d$ & $e / d$ & $s / d$ \\
\hline & 6.35 & 1.5 & 1.5 & 2 & 1.5 & 2 & 1.5 & 2.5 & 2.5 \\
$\mathrm{~A} 307$ & 9.53 & 1.5 & 1.5 & 1.5 & 1.5 & 1.5 & 1.5 & 2 & 1.5 \\
& 12.7 & 1.5 & 1.5 & 1.5 & 1.5 & 1.5 & 1.5 & 1.5 & 1.5 \\
& 25.4 & 1.5 & 1.5 & 1.5 & 1.5 & 1.5 & 1.5 & 1.5 & 1.5 \\
\hline & 6.35 & 3 & 2 & 3.5 & 2.5 & - & - & - & - \\
& 9.53 & 2 & 1.5 & 2 & 2 & 2.5 & 2.5 & 4 & 3 \\
A325 & 12.7 & 1.5 & 1.5 & 2 & 1.5 & 2 & 1.5 & 2.5 & 2.5 \\
& 15.88 & 1.5 & 1.5 & 1.5 & 1.5 & 1.5 & 1.5 & 2 & 2 \\
& 19.05 & 1.5 & 1.5 & 1.5 & 1.5 & 1.5 & 1.5 & 2 & 1.5 \\
& 25.4 & 1.5 & 1.5 & 1.5 & 1.5 & 1.5 & 1.5 & 1.5 & 1.5 \\
\hline & 6.35 & 3 & 3 & - & - & - & - & - & - \\
& 9.53 & 2 & 2 & 3 & 2 & 3.5 & 2.5 & - & - \\
& 12.7 & 1.5 & 2 & 2 & 2 & 2.5 & 2 & 3.5 & 2.5 \\
A490 & 15.88 & 1.5 & 1.5 & 2 & 1.5 & 2 & 1.5 & 3 & 2 \\
& 19.05 & 1.5 & 1.5 & 1.5 & 1.5 & 2 & 1.5 & 2 & 2 \\
& 22.22 & 1.5 & 1.5 & 1.5 & 1.5 & 1.5 & 1.5 & 2 & 1.5 \\
& 25.4 & 1.5 & 1.5 & 1.5 & 1.5 & 1.5 & 1.5 & 2 & 1.5 \\
\hline
\end{tabular}


Table 8. Optimum parameters for two-bolt in a column $(e=2 d)$

\begin{tabular}{cccccc}
\hline Bolt $t$ & $d=12.7 \mathrm{~mm}$ & $d=15.88 \mathrm{~mm}$ & $d=19.05 \mathrm{~mm}$ & $d=25.4 \mathrm{~mm}$
\end{tabular}

\begin{tabular}{cccccccccc} 
grade & $(\mathrm{mm})$ & $p / d$ & $s / d$ & $p / d$ & $s / d$ & $p / d$ & $s / d$ & $p / d$ & $s / d$ \\
\hline 6.4 & 2 & 2 & 2 & 3 & 2 & 3 & 2 & 4
\end{tabular}

\begin{tabular}{|c|c|c|c|c|c|c|c|c|c|}
\hline \multirow{3}{*}{ A307 } & 9.5 & 2 & 1.5 & 2 & 1.5 & 2 & 2 & 2 & 3 \\
\hline & 12.7 & 2 & 1.5 & 2 & 1.5 & 2 & 1.5 & 2 & 2 \\
\hline & 25.4 & 2 & 1.5 & 2 & 1.5 & 2 & 1.5 & 2 & 1.5 \\
\hline \multirow{6}{*}{ A325 } & 6.4 & 3 & 3 & - & - & - & - & - & - \\
\hline & 9.5 & 2 & 3 & 2 & 3 & 2 & 4 & - & - \\
\hline & 12.7 & 2 & 2 & 2 & 3 & 2 & 3 & 2 & 4 \\
\hline & 15.9 & 2 & 1.5 & 2 & 2 & 2 & 3 & 2 & 3 \\
\hline & 19.1 & 2 & 1.5 & 2 & 1.5 & 2 & 2 & 2 & 3 \\
\hline & 25.4 & 2 & 1.5 & 2 & 1.5 & 2 & 1.5 & 2 & 2 \\
\hline \multirow{6}{*}{ A490 } & 9.5 & 2 & 3 & 3 & 4 & - & - & - & - \\
\hline & 12.7 & 2 & 3 & 2 & 3 & 2 & 4 & - & - \\
\hline & 15.9 & 2 & 2 & 2 & 3 & 2 & 3 & 2 & 4 \\
\hline & 19.1 & 2 & 1.5 & 2 & 2 & 2 & 3 & 2 & 3 \\
\hline & 22.2 & 2 & 1.5 & 2 & 2 & 2 & 2 & 2 & 3 \\
\hline & 25.4 & 2 & 1.5 & 2 & 1.5 & 2 & 2 & 2 & 3 \\
\hline
\end{tabular}

800

801 
802

Table 9. Optimum parameters for two-bolt in row $(s=3 d)$

\begin{tabular}{cccccccccc}
\hline Bolt & $t$ & \multicolumn{2}{c}{$d=12.7 \mathrm{~mm}$} & \multicolumn{2}{c}{$d=15.88 \mathrm{~mm}$} & \multicolumn{2}{c}{$d=19.05 \mathrm{~mm}$} & \multicolumn{2}{c}{$d=25.4 \mathrm{~mm}$} \\
\cline { 3 - 10 } grade & $(\mathrm{mm})$ & $g / d$ & $e / d$ & $g / d$ & $e / d$ & $g / d$ & $e / d$ & $g / d$ & $e / d$ \\
\hline \multirow{4}{*}{ A307 } & 6.4 & 2 & 1.5 & 2 & 1.5 & 3 & 1.5 & 3 & 3 \\
& 9.5 & 2 & 1.5 & 2 & 1.5 & 2 & 1.5 & 2 & 2 \\
& 12.7 & 2 & 1.5 & 2 & 1.5 & 2 & 1.5 & 2 & 1.5 \\
& 25.4 & 2 & 1.5 & 2 & 1.5 & 2 & 1.5 & 2 & 1.5 \\
\hline \multirow{4}{*}{ A325 } & 6.4 & 3 & 2.75 & 4 & 3 & - & - & - & - \\
& 9.5 & 3 & 1.5 & 3 & 2 & 3 & 3 & 5 & 3 \\
& 12.7 & 2 & 1.5 & 2 & 1.5 & 3 & 1.5 & 3 & 3 \\
& 15.9 & 2 & 1.5 & 2 & 1.5 & 2 & 1.5 & 3 & 2 \\
& 19.1 & 2 & 1.5 & 2 & 1.5 & 2 & 1.5 & 3 & 1.5 \\
\hline \multirow{4}{*}{ A490 } & 6.4 & 4 & 3 & - & - & - & - & - & - \\
& 9.5 & 4 & 1.5 & 4 & 2 & 4 & 3 & - & - \\
& 12.7 & 2 & 1.5 & 3 & 3 & 3 & 2 & 4 & 3 \\
& 15.9 & 2 & 1.5 & 3 & 1.5 & 3 & 1.5 & 3 & 3 \\
& 19.1 & 2 & 1.5 & 2 & 1.5 & 2 & 1.5 & 3 & 2 \\
& 22.2 & 2 & 1.5 & 2 & 1.5 & 2 & 1.5 & 3 & 1.5 \\
\hline
\end{tabular}

803

804

805 